\title{
An Idealized Model and Systematic Process Study of Oxygen Depletion in Highly Turbid Estuaries
}

\author{
S. A. Talke • H. E. de Swart • V. N. de Jonge
}

Received: 11 June 2008 /Revised: 15 April 2009 /Accepted: 19 April 2009/Published online: 27 May 2009

(C) Coastal and Estuarine Research Federation 2009

\begin{abstract}
The sensitivity of oxygen depletion in turbid estuaries to parameters like freshwater discharge, depth, and sediment availability is investigated using an idealized model. The model describes tidally averaged circulation and suspended sediment concentration (SSC), which are input into an advection-diffusion sink module of dissolved oxygen (DO). Based on the analysis of field data collected in the Ems estuary, the modeled oxygen depletion rates are proportional to SSC. The model is calibrated to the observed variation of DO with SSC and temperature. Modeled DO closely tracks changes to the estuarine turbidity zone (ETZ): increased channel depth, decreased freshwater discharge, and decreased mixing move the ETZ upstream, amplify SSCs, and decrease DO. Summertime temperatures produce lower DO than cooler periods. Model results are consistent with historical measurements in the Ems, which indicate that hypoxic events (DO concentrations $<2 \mathrm{mg} \mathrm{l}^{-1}$ ) have occurred more frequently after deepening from 5 to $7 \mathrm{~m}$.
\end{abstract}

Electronic supplementary material The online version of this article (doi:10.1007/s12237-009-9171-y) contains supplementary material, which is available to authorized users.

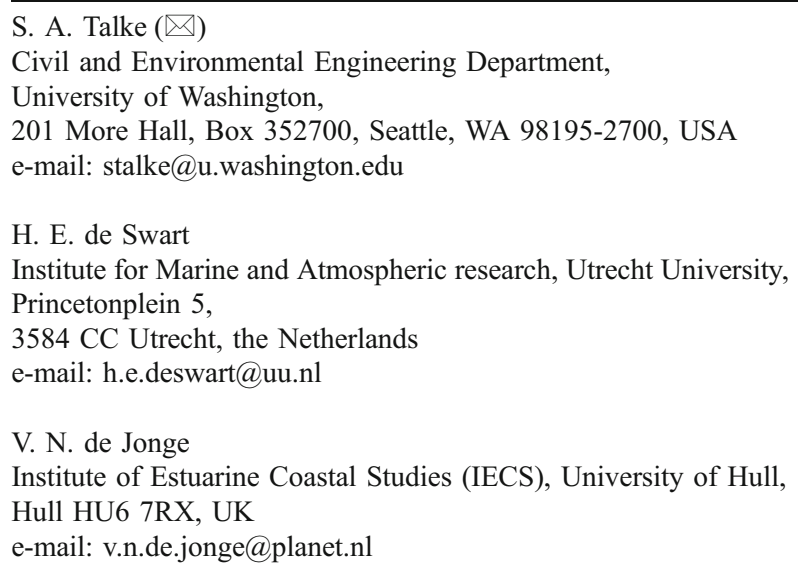

e-mail: v.n.de.jonge@planet.nl

Keywords Estuarine circulation · Estuarine turbidity maximum · Sediment dynamics · Morphology · Fluid mud · Water quality $\cdot$ Hypoxia $\cdot$ Anoxia $\cdot$ Ems estuary

\section{Introduction}

Depleted levels of dissolved oxygen (DO) occur in many Asian estuaries (Fang and Lin 2002; Dai et al. 2006; Ni et al. 2007), North American estuaries (Engle et al. 1999; Borsuk et al. 2001; Hagy et al. 2004; Benoit et al. 2006; Lin et al. 2006), and European estuaries (Uncles et al. 1998; Garnier et al. 2001). These zones of hypoxia (DO concentration $<2 \mathrm{mg}^{-1}$ ) greatly degrade environmental conditions for benthic and pelagic fauna and alter redox conditions, which changes the cycling of nutrients and partitioning of pollutants throughout the estuary (de Jonge and Villerius 1989; Diaz and Rosenburg 1995; Nestlerode and Diaz 1998; Fang and Lin 2002). Given the ecological consequences of hypoxic and anoxic conditions, there is a strong need to understand, on a process level, the physical and biological processes that are contributing to this problem.

In many estuaries, oxygen depletion is tied to the inputs of organic matter caused by effluent, industry, or natural causes (Hagy et al. 2004; Dai et al. 2006; Fang and Lin 2002; Wei et al. 2007). Other estuaries such as the Humber Estuary, Loire Estuary, and Yellow River Estuary show evidence of oxygen depletion due to the degradation of organic matter that is associated with the suspended sediment aggregates (Uncles et al. 1998; Thouvenin et al. 1994; Ni et al. 2007). Physical processes which affect DO concentrations include vertical mixing and stratification, river discharge, and baroclinic circulation. In the Chesapeake Bay region, high river inflow causes greater influx 
of nutrients, greater primary production, and subsequent depletion of DO (Hagy et al. 2004; Lung and Nice 2007). In other estuaries, hypoxic conditions occur during lowinflow conditions and are attributed to the increased residence time of water (Dai et al. 2006; Hagy and Murrell 2007). Vertical mixing often controls DO, with depletion occurring in highly stratified systems (Borsuk et al. 2001; Lin et al. 2006; Hagy and Murrell 2007). Finally, an idealized analytical model and a box model show that gravitational circulation, which drives near-bed flows of oxygenated seawater into the estuary, also alters the oxygen budget of estuaries (Lin et al. 2006; Hagy and Murrell 2007).

In this paper, we investigate oxygen depletion that occurs in the estuarine turbidity zone (ETZ) of the Ems estuary. Before the 1980s, hypoxic conditions occurred primarily in the Dollard subbasin from the discharge of organic matter (e.g., sewage effluent), particularly when low freshwater discharge resulted in a large residence time of water (Helder and Ruardij 1982). Though sanitation measures greatly reduced the organic load and oxygen depletion in the Dollard (Essink 2003), we present measurements which show that low DO concentrations are increasingly being measured in the brackish and freshwater portions of the river Ems, upstream of the Dollard. Using a combination of field measurements and modeling, we investigate the cause of the renewed water quality problem, focusing on the connection between depleted DO and increased suspended sediment concentrations (SSCs) in the turbidity zone. The physical mechanisms behind decreasing DO concentrations and increased turbidity are investigated with an idealized tidally averaged model that estimates circulation, SSC (organic matter), and DO concentrations. Estuarine geometry, physical, and biological processes are simplified to investigate first-order effects and result in a model of oxygen depletion that is transparent, computationally fast, and flexible. Using sensitivity studies, we identify key parameters that govern observations. For turbid estuaries, we show that the along-channel distribution of organic material — which is set by the sediment dynamics of turbidity zones-governs the depletion of DO.

\section{Observational Background}

The Ems-Dollard estuary, located on the border of the Netherlands and Germany, is forced by semidiurnal tides with tidal ranges increasing from $2.3 \mathrm{~m}$ at the inlet to $\sim 3.5 \mathrm{~m}$ in the river (Fig. 1). Approximately $80 \%$ of the Dollard subbasin and $\sim 50 \%$ of the entire estuary is covered by tidal flats. Channel depth is maintained at a navigable depth of $8 \mathrm{~m}$ from the barrier island of Borkum $(\mathrm{km} \mathrm{0})$ to the harbor town of Emden ( $\mathrm{km} \mathrm{46}$; Krebs and Weilbeer 2008), with a maximum depth of $\sim 30 \mathrm{~m}$, and is maintained at $\sim 7 \mathrm{~m}$ depth for shipping between Emden and Papenburg ( $\mathrm{km} \mathrm{87).} \mathrm{A} \mathrm{tidal} \mathrm{weir} \mathrm{at} \mathrm{Herbrum} \mathrm{(km} \mathrm{100)} \mathrm{marks} \mathrm{the} \mathrm{end}$ of tidal influence. Freshwater discharge average varies from 10 to $40 \mathrm{~m}^{3} \mathrm{~s}^{-1}$ during the summer months to a maximum of $\sim 600 \mathrm{~m}^{3} \mathrm{~s}^{-1}$ during wet winter periods (yearly average is $\left.80-110 \mathrm{~m}^{3} \mathrm{~s}^{-1}\right)$. The watershed of the Ems contains large areas of peat, which lead to highly refractory organic

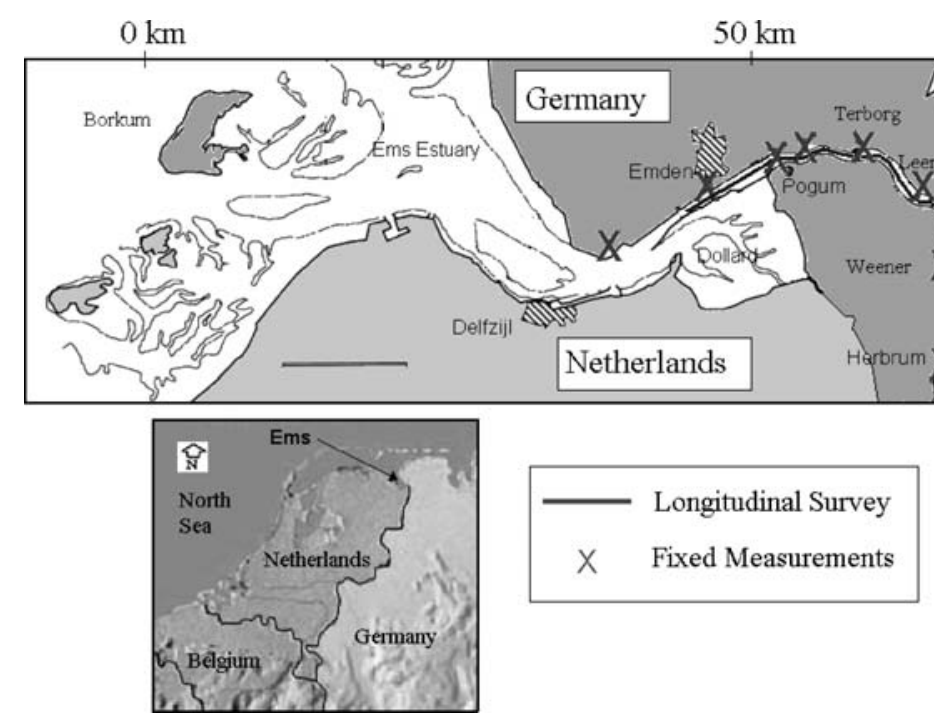

Fig. 1 Map of the Ems-Dollard estuary. Location of the longitudinal transect between Emden and Herbrum is shown, along with the location of a cross-sectional cruise near Pogum. The locations of longterm monitoring stations by the NLWKN are shown with an $X$. Moving downstream from Herbrum, these stations are: (a) Herbrum (km 100), (b) Papenburg km 86.9, (c) Weener (km 80.4), (d) LeerLeda (3.9 km upstream of $\mathrm{km} \mathrm{73.3),} \mathrm{(e)} \mathrm{Leerort} \mathrm{(} \mathrm{km} \mathrm{72.6),} \mathrm{(f)} \mathrm{Terborg}$ (km 62.7), (g) Gandersum (km 55.6), (h) Pogum (km 52), (i) Emden (km 46.1), and (j) Knock ( $\mathrm{km} \mathrm{36.4).} \mathrm{The} \mathrm{Dollard} \mathrm{is} \mathrm{separated} \mathrm{from} \mathrm{the}$ main channel of the Ems river by a semiporous dike (the "Geisedam") 
material in the estuary (van Es et al. 1980; Baretta and Ruardij 1988). Water temperature varies from $0^{\circ} \mathrm{C}$ to $25^{\circ} \mathrm{C}$ between winter and summer.

We use a combination of moored monitoring data, and cruise data to analyze oxygen depletion. For the years 2005-2006, salinity, SSC, temperature, freshwater discharge, and DO concentration measurements at 5-30-min increments were made available at eight stations along the Ems by the Niedersächsisches Landesbetrieb für Wasserwirtschaft, Küsten-und Naturschutz (NLWKN), part of the German state of Niedersachsen (see Fig. 1). We also use historical measurements of salinity, DO, and temperature from the stations at Leer-Leda (located $3.9 \mathrm{~km}$ upstream of Ems km 73.3 on the Leda tributary) and Terborg (km 62.7), which are available from 1984 to 2000 and 1988 to 2000 , respectively, from the NLWKN. Historical measurements of turbidity and SSC are available at Leer-Leda and Terborg, respectively, from 1998 to 2000.

Beginning in February 2005 and running through December 2007, 30 (nearly) monthly measurements of water quality and biological parameters were made along the longitudinal axis of the Ems estuary using a shipboard flow-through system (see Fig. 1). On selected cruises, we measured vertical profiles of turbidity, salinity, temperature, and DO concentration using an RBR conductivity-temperature-depth (CTD) sensor with an attached DO sensor. Profiles of velocity and backscatter were also made with an RDI workhorse ADCP. Water samples from each cruise were filtered using a Whatman GF/C filter to determine the SSCs and calibrate the OBS using the method of Kineke and Sternberg (1992). Here, we focus on CTD/DO casts obtained during a cruise between $\mathrm{km} 45$ (near the port of Emden) and km 100 (the tidal weir at Herbrum) on Aug. 2, 2006 during low-freshwater-discharge conditions (see
Figs. 2 and 3). The outgoing cruise progressed upstream with the ebb tidal wave (against the current), beginning at $4 \mathrm{~h}$ before the local Low Water (LW) slack and ending at local LW slack. The return cruise progressed against the flood tide wave (against the current), starting about $2 \mathrm{~h}$ after local LW ( $\sim 3.5 \mathrm{~h}$ before HW slack) and ending $\sim 30 \mathrm{~min}$ after local HW slack. Overall, 25 CTD/DO casts were made in $2-3-\mathrm{km}$ increments during the outgoing ebb cruise and 14 casts were made during the return flood cruise. Measurements near each other, particularly at the important transition from turbid to clear conditions and marine to freshwater, are nearly synoptic (see Figs. 2 and 3); more information is available in Talke et al. (2009).

\section{Field Results}

Measurements along the longitudinal axis of the Ems estuary from Aug. 2, 2006 show evidence of widespread hypoxia $\left(\mathrm{DO}<2 \mathrm{mg} \mathrm{l}^{-1}\right)$ and wide variation in SSCs $\left(0.3-80 \mathrm{~kg} \mathrm{~m}^{-3}\right)$ during both ebb (Fig. 2) and flood (Fig. 3) tides. Water is relatively clear $\left(\mathrm{SSC}<0.5 \mathrm{~kg} \mathrm{~m}^{-3}\right)$ in the more marine portion of the estuary (salinity $>10 \mathrm{psu}$ ) but is extremely turbid with large SSCs and fluid mud $\left(10-80 \mathrm{~kg} \mathrm{~m}^{-3}\right)$ in the brackish regions (salinity $<2 \mathrm{psu}$ ). The elevated $\mathrm{SSC}$, which forms an ETZ from the toe of the salt wedge ( $\mathrm{km} 65$ to 75$)$ to the tidal weir ( $\mathrm{km} \mathrm{100),} \mathrm{coincides} \mathrm{with} \mathrm{a} \mathrm{zone} \mathrm{of} \mathrm{depleted}$ DO with concentrations less than $5 \mathrm{mg} \mathrm{l}^{-1}$ (with a minimum below $1 \mathrm{mg}^{-1}$ ). More saline water (salinity $>5 \mathrm{psu}$ ) is well oxygenated. Both SSC and DO vary vertically, with SSC increasing exponentially towards the bed (see Supplement S.2) and DO as much as $2 \mathrm{mg} \mathrm{l}^{-1}$ greater at the surface than near the bed. Salinity over most of the estuary is vertically well mixed or partially mixed. The depleted DO zone persists during both the ebb and the flood,
Fig. 2 Salinity (a), $\operatorname{SSC}$ (b), and dissolved oxygen concentration (c) as a function of depth below the surface along the longitudinal axis of the Ems estuary (kilometer from North Sea) during the ebb of Aug. 2, 2006. Results are interpolated between 25 casts of the CTD/ OBS/oxygen sensor, whose locations are shown by vertical dotted lines. The plots of salinity and SSC are reproduced from Talke et al. (2009)
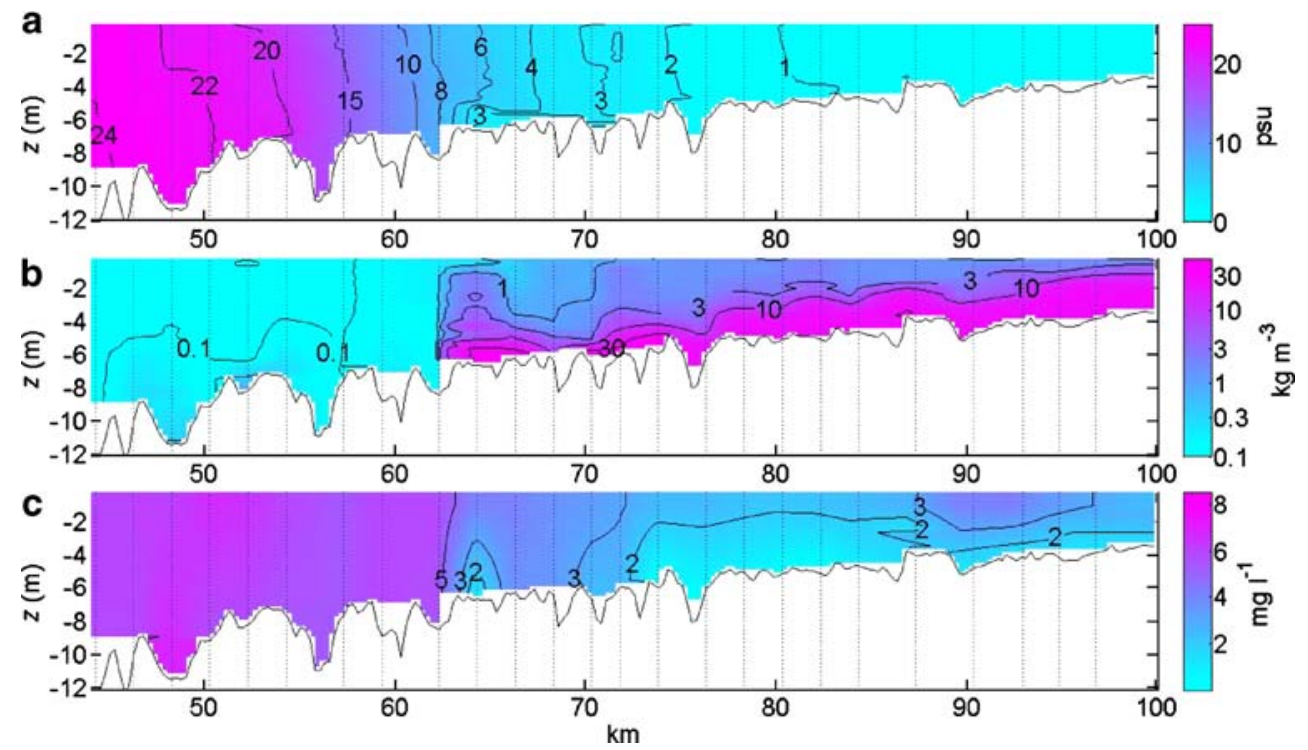
Fig. 3 Salinity (a), SSC (b), and dissolved oxygen concentration (c) as a function of depth below the surface and the longitudinal position along the Ems estuary (kilometer from North Sea) during the flood tide on Aug. 2, 2006. Plot follows format of Fig. 3. Differences in bathymetry and water depth between Figs. 2 and 3 reflect differences in ship course and tidal stage. The salinity and SSC plots are adapted from Talke et al. (2009)
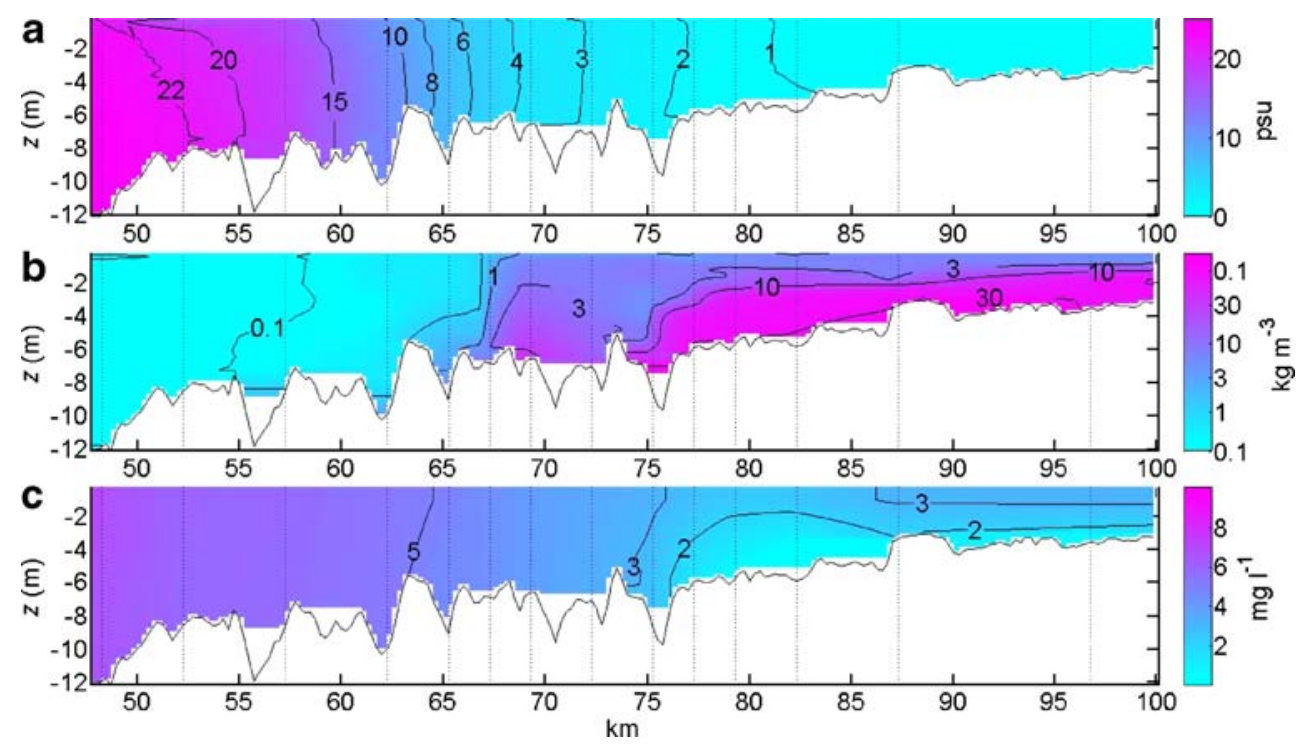

over different phases of the tidal wave. As sediment moves upstream during the flood tide in Fig. 2, the zone of depleted oxygen also moves upstream (compare Figs. 2 and 3). Other spatial patterns of SSC, such as the local maximum in SSC at $\mathrm{km} 65$ during the ebb, also correspond with reduced oxygen concentration (Fig. 2). The overall minimum DO during the quasisynoptic ebb cruise is located at $\mathrm{km} 73.8$, about $3.5 \mathrm{~km}$ upstream of the
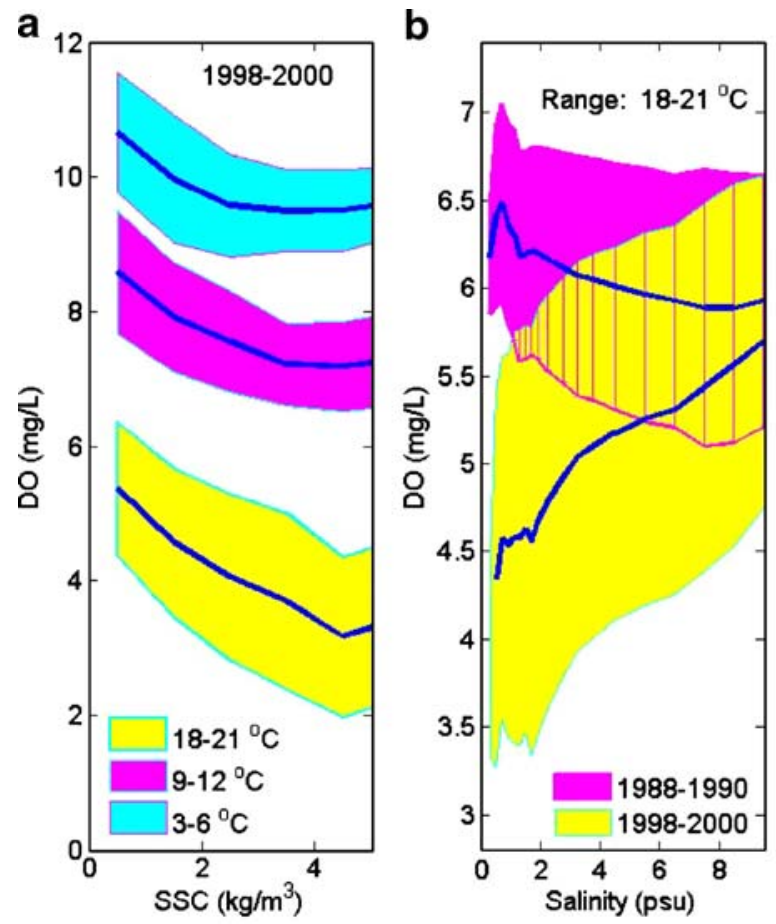

Fig. 4 Measurements from the fixed station in Terborg at $62.7 \mathrm{~km}$ showing variation in DO vs. SSC for 1998-2000 (a), DO vs. salinity for 1988-1990 and 1998-2000 (b), SSC vs. salinity for 1998-2000 (c), and the time period, measured in days, that DO was below 2 and $5 \mathrm{mg} \mathrm{l}^{-1}$ maximum SSC of $\sim 80 \mathrm{~kg} \mathrm{~m}^{-3}$ (Fig. 2). Water temperatures ranged from $21^{\circ} \mathrm{C}$ (marine water) to $24^{\circ} \mathrm{C}$ (at the weir).

The observed relationship between high SSC and depleted oxygen concentrations indicates that organic matter in the fluid mud is controlling the depletion of oxygen in the water column, as also observed in other turbid estuaries such as the Humber (Uncles et al. 1998). Historical measurements at two fixed stations confirm that

C
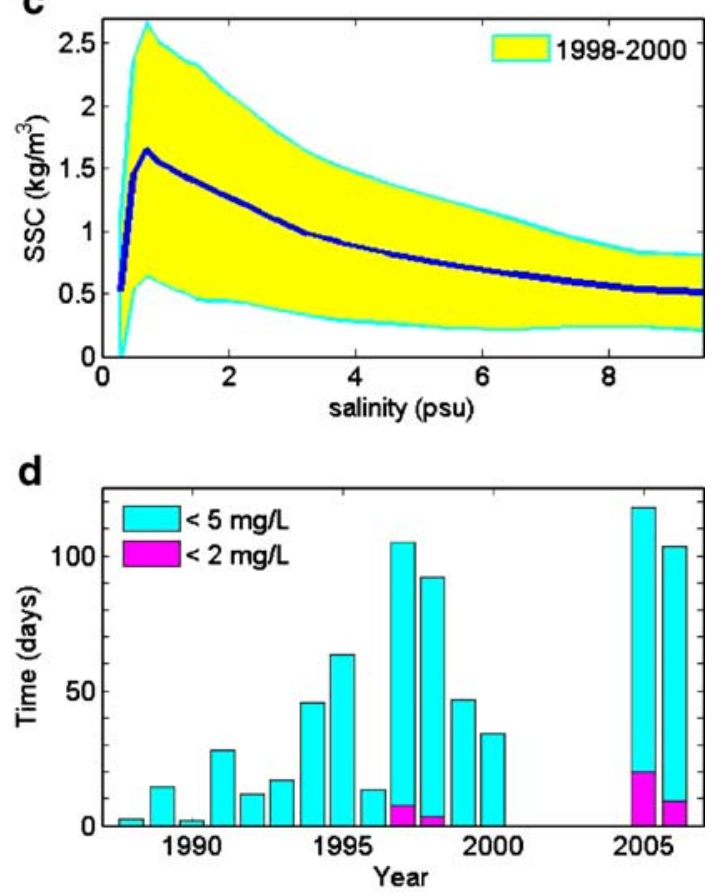

(d). The bin-averaged data are depicted by solid lines in $\mathbf{a}, \mathbf{b}$, and $\mathbf{c}$, and the standard deviation is depicted with an envelope. For $\mathbf{a}$ and $\mathbf{b}$, data were also binned into the depicted temperature ranges. Measurements were collected by the NLWKN at a height of $1.5 \mathrm{~m}$ above the bed 

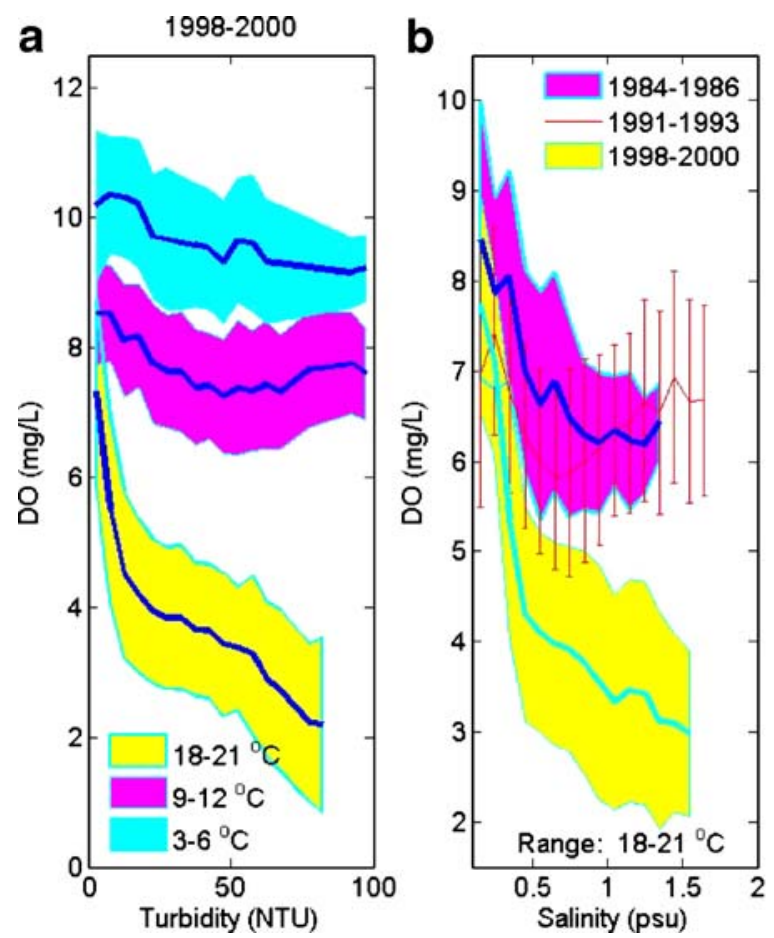

Fig. 5 Measurements from the fixed station in Leer-Leda showing variation in DO vs. turbidity for 1998-2000 (a), DO vs. salinity for 19841986, 1991-1993, and 1998-2000 (b), turbidity vs. salinity for 19982000 (c), and the time period, measured in days, that DO was below 2 and $5 \mathrm{mg}^{-1}$ (d). The bin-averaged data are depicted by solid lines in $\mathbf{a}$,

oxygen depletion correlates well with SSC (Figs. 4 and 5). Figures $4 \mathrm{a}$ and $5 \mathrm{a}$ show envelopes of the average DO and its standard deviation as a function of SSC, with DO measurements separated into water temperature bins reflecting typical summer conditions $\left(18-21^{\circ} \mathrm{C}\right)$, spring and autumn conditions $\left(9-12^{\circ} \mathrm{C}\right)$ and winter conditions $\left(0-3^{\circ} \mathrm{C}\right)$. At both locations, DO concentrations decrease approximately linearly with increasing SSC (Fig. 4a) and turbidity (proportional to SSC; Fig. 5a), although the slope decreases slightly at higher SSC. Dissolved oxygen concentrations are a strong function of temperature: colder water is more oxygenated at zero SSC and the rate of depletion as a function of SSC is smaller. Significant variation (standard deviation of approximately $\pm 1 \mathrm{mg} \mathrm{l}^{-1}$ ) is found in the trends observed in Figs. 4a and 5a. A partial list of possible causes includes changing aeration due to wind, variable mixing due to tides (e.g., spring-neap), advection and diffusion from upstream and downstream, recent conditions (e.g., conditions over the previous time period), changes in biological factors, or other sources of DO depletion (e.g., patchiness in distribution of organic material or microorganisms). Nonetheless, to first order, the depletion of DO can be considered to be proportional to SSC.

The SSC which causes DO depletion is typically trapped within an estuarine turbidity zone which is centered within
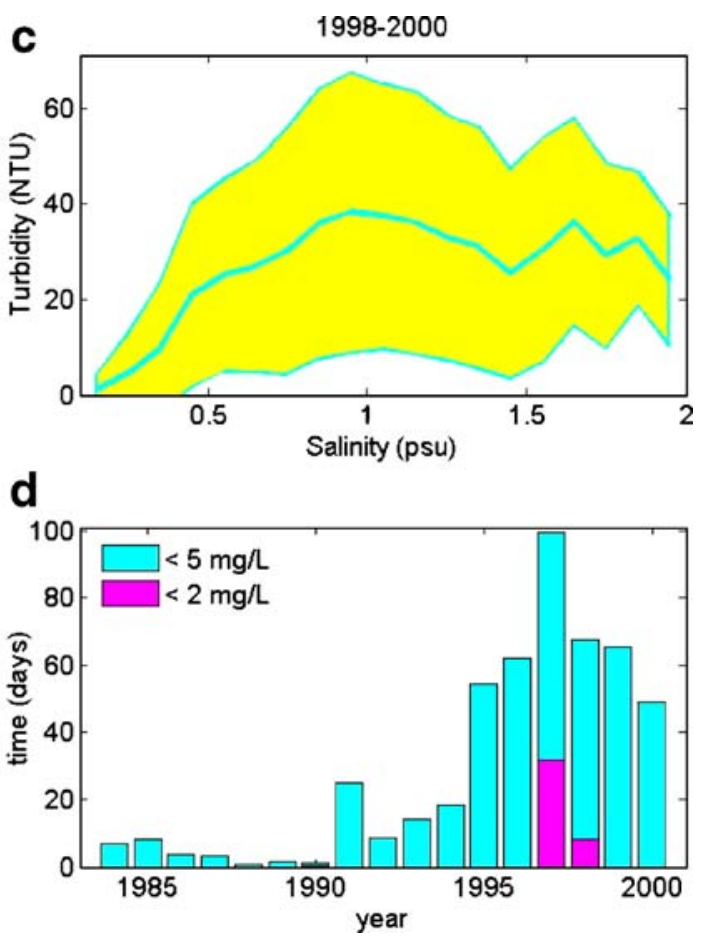

$\mathbf{b}$, and $\mathbf{c}$, and the standard deviation is depicted with an envelope or bars. For $\mathbf{a}$ and $\mathbf{b}$, data were also binned into the depicted temperature ranges. Measurements were collected by the NLWKN at a height of $1 \mathrm{~m}$ below the water surface. The station is located approximately $3.9 \mathrm{~km}$ from the discharge of the Leda into the Ems at $73.3 \mathrm{~km}$

a band of salinity between 0.5 and 2 psu (Figs. $4 \mathrm{c}$ and $5 \mathrm{c}$ ). At low salinity $(<0.3 \mathrm{psu})$, which occurs during elevated freshwater discharge at these locations, SSC and turbidity decrease markedly. Conversely, the salt wedge moves upstream during low discharge and the measured SSC decreases as salinity increases ( $>2 \mathrm{psu}$ ). Because the station of Leer-Leda (Fig. 5) is nearly $15 \mathrm{~km}$ upstream of Terborg (Fig. 4), salinity there does not exceed 2 psu.

The SSC and turbidity distribution suggest a conceptual picture in which organic material (attached to SSC) produces a sag (minimum) in the along-estuary distribution of DO, with more oxygenated conditions observed at the freshwater and saline boundaries of the ETZ (see also Figs. 2 and 3). Such a DO sag is confirmed by contemporary measurements from 1998 to 2000, which shows that DO concentrations increase markedly during freshwater conditions (Fig. 5b) and more marine conditions (Fig. 4b), with minimum DO concentrations occurring in brackish water between 0.5 and 2 psu. Comparison with historical measurements from 1988 to 1990 (Fig. 4b) and 1984 to 1986 (Fig. 5b) shows a downwards shift in DO in the ETZ over time of between 1 and $3 \mathrm{mg} \mathrm{l}^{-1}$, on average. No significant change in DO is observed at the boundaries of the ETZ. Hence, though historical measurements of SSC are unavailable, the results indicate that the increased 
contemporary depletion of oxygen in the ETZ is likely occurring because of increased SSC (and not other factors). The majority of increased oxygen demand apparently occurred after 1993 since mean DO concentrations in 19911993 are only slightly less than 1984-1986 (Fig. 5b). The decrease in DO concentrations (particularly after 1994) coincides with progressive deepening of the river Ems in 1985-1986, 1991-1992, and 1994 from $\sim 5 \mathrm{~m}$ to $\sim 7 \mathrm{~m}$ between Emden ( $\mathrm{km} \mathrm{46}$ ) and Papenburg ( $\mathrm{km} \mathrm{87}$; Jensen et al. 2003) and increased maintenance dredging (de Jonge 2000).

The worsening DO conditions over the past two decades are confirmed by considering the time (measured in days per year) that DO concentrations are below the threshold of 5 and $2 \mathrm{mg} \mathrm{l}^{-1}$ (Figs. 4d and 5d). Whereas less than 20 days/year dipped below the $5 \mathrm{mg}^{-1}$ threshold before 1991 at either station, conditions worsen to a high of $\sim 118$ days in 2005 at Terborg (data were unavailable past 2000 for Leer-Leda). Hypoxic conditions $\left(<2 \mathrm{mg}^{-1}\right)$ never occurred at either station before 1997 but are becoming increasingly common and are occurring for longer time periods ( $\sim 20$ days in 2005). Because DO concentrations of 5 and $2 \mathrm{mg} \mathrm{l}^{-1}$ are thresholds below which many fish and other organisms become stressed or killed, respectively, the environmental quality of the river Ems has clearly degraded.

Because the DO sag in the Ems estuary is linked to the magnitude of SSC and its longitudinal distribution, understanding the physical factors which change the ETZ (e.g., freshwater discharge or water depth) becomes essential for understanding DO dynamics. The persistence of elevated SSC and depressed DO during both the flood and ebb (Figs. 2 and 3) suggests that a tidally averaged model can capture the subtidal distribution of SSC and DO. To identify and understand the physical factors controlling oxygen depletion, we next develop an idealized model for the distribution of SSC and DO in an estuary.

\section{Model}

The oxygen depletion model we develop for an idealized estuary uses analytical solutions to tidally averaged circulation and SSCs developed by Talke et al. (2008, 2009). Here, we first outline the hydrodynamic and morphodynamic models (more details are available in Supplement S.1) and then develop the DO concentration model.

\section{Hydrodynamic and SSC Model}

The tidally averaged hydrodynamic model of Talke et al. $(2008,2009)$ extends the classical definition of estuarine circulation (Hansen and Rattray 1965; Officer 1976) to include currents that arise due to longitudinal density gradients of SSC. The model applies the rigid-lid assumption, assumes no slip at the bottom boundary and no shear at the top, and assumes that eddy viscosity $A_{v}$, eddy diffusivity $K_{v}$, depth $H$, longitudinal dispersion $K_{h}$, and the settling velocity $w_{\mathrm{s}}$ of sediment particles are constant throughout the model domain (see Fig. 6 for a review of key assumptions). The $x$-axis points upstream and the origin $x=0$ is at the seaward boundary. The $z$-axis points upwards from the water surface. Following other idealized studies (e.g., Friedrichs et al. 1998), we define a funnelshaped estuary such that the development of width $b$ with distance is described by an exponential function,

$$
b(x)=B_{o} \exp \left(\frac{-x}{L_{e}}\right)
$$

where $B_{o}$ is the width at the estuary mouth $(x=0)$ and $L_{e}$ is the convergence length scale of the estuary. Following Odd (1988), the equation of state for the model is a linearized function of both salinity $s(x)$ and suspended sediment concentration $C(x, z)$ :

$\rho(x, z)=\rho_{o}+\beta s(x)+\gamma C(x, z)$.

In this expression, $\rho(x, z)$ is the combined density $\left(\mathrm{kg} \mathrm{m}^{-3}\right)$; $\rho_{o}\left(\mathrm{~kg} \mathrm{~m}^{-3}\right)$ is the density of water; $\beta$ is $\sim 0.83 \mathrm{~kg} \mathrm{~m}^{-3} \mathrm{psu}^{-1}$ and converts salt to density and $\gamma=\left(\rho_{s}-\rho_{o}\right) / \rho_{s} \sim 0.62$ converts SSC into density, where $\rho_{s}$ is the density of the sediment particles, here assumed to be sand for simplicity. We assume that salinity is well mixed vertically (as suggested by Figs. 2 and 3) and is described longitudinally by a hyperbolic tangent (see also Warner et al. 2005):

$$
s(x)=0.5 S_{o}\left\{1-\tanh \left(\frac{x-x_{c}}{x_{L}}\right)\right\}
$$

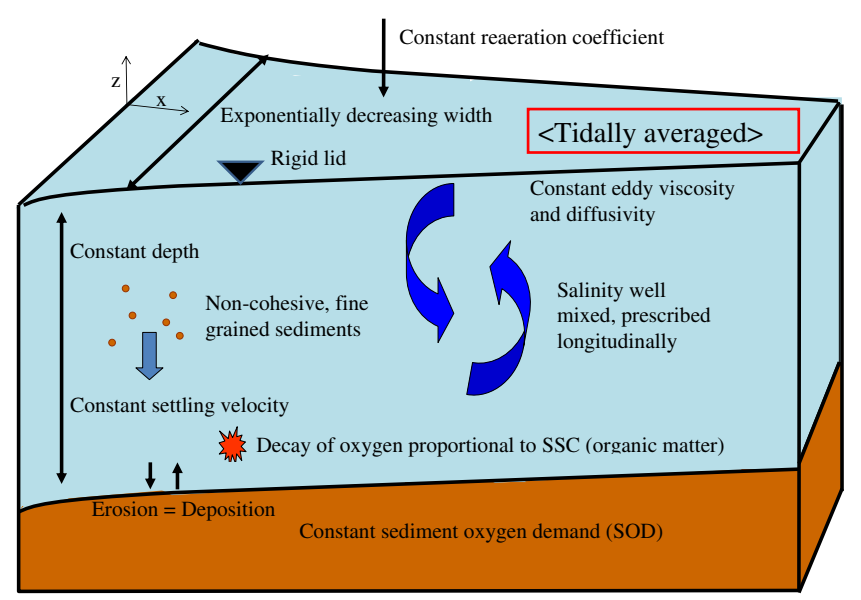

Fig. 6 Assumptions made during derivation of model 
where $S_{o}$ (psu) is the salinity at the seaward boundary; $x_{c}[\mathrm{~m}]$ is the position of the maximum salinity gradient, and $x_{L}(\mathrm{~m})$ scales the slope of the salinity gradient. The parameters $x_{c}$ and $x_{L}$ are functions of freshwater discharge, as summarized in Table 1 and described in more detail in Supplement S.1.

The vertical distribution of SSC is modeled as an exponential profile, a consequence of assuming that the settling flux of particles is balanced by an upward flux from turbulent diffusion:

$C(x, z)=c_{b}(x) \exp \left\{\frac{-w_{s}}{K_{v}}(z+H)\right\}$,

where $c_{b}(x)$ is a function describing the distribution of SSC at the bed (located at $z=-H$ ) in the longitudinal direction. As described in Supplement S.2, SSC measurements at a fixed location in Feb. 2006 show that, to first order, an exponential profile of SSC with depth is a valid approximation over a tidal period. We assume that, to first order, there are no tidally averaged transverse variations in SSC.

The tidally averaged momentum equation describes a balance between the barotropic pressure gradient induced by the time-averaged surface slope and the pressure gradient induced by the combined longitudinal variation in SSC and salinity (Eq. 2). Further, the cross-sectionally integrated flow at each point $x$ is set equal to the freshwater discharge $Q$ (which is taken as negative in our coordinate system). Solving these expressions with appropriate boundary conditions, as discussed in more detail in Supplement S.1, yields:

$$
\begin{aligned}
u(x, \zeta)= & \underbrace{\frac{g \beta H^{3}}{48 \rho_{o} A_{v}} k_{1}(\zeta) \frac{d s}{d x}}_{\text {baroclinic circulation }}+\underbrace{\frac{g \gamma H^{3}}{48 \rho_{o} A_{v}} k_{2}\left(\zeta, P e_{v}\right) \frac{d c_{b}}{d x}}_{\text {SSC induced circulation }} \\
& +\underbrace{\frac{3 Q}{2 b(x) H}\left(1-\zeta^{2}\right)}_{\text {freshwater circulation }},
\end{aligned}
$$

where $\zeta=z / H$ is the nondimensional height; $g$ is gravity, and $P e_{v}=w_{s} H / K_{v}$ is the vertical Peclet number for SSC. The first term on the rhs of Eq.5 is baroclinic circulation due to the prescribed salinity gradient $\mathrm{d} s / \mathrm{d} x$; the second term is circulation due to gradients in bottom $\mathrm{SSC}\left(\mathrm{d} c_{b} / \mathrm{d} x\right)$, and the third term is the contribution of freshwater discharge and is a function of the width $b(x)$. The vertical structure of flows driven by longitudinal salinity gradients and longitudinal SSC gradients are described by the functions $k_{1}$ and $k_{2}$, respectively, and are defined in the appendix. When $\mathrm{d} c_{b} / \mathrm{d} x$ is set to zero and $b(x)$ is constant, the gravitational circulation model of Hansen and Rattray (1965) is recovered. Flow is assumed uniform over the width.

The function $c_{b}(x)$ is found by first assuming that the model estuary is in morphodynamic equilibrium, i.e., that tidally averaged SSC concentrations over time are constant for a given set of parameters (more detail is given in Supplement S.1). Morphodynamic equilibrium occurs when net sediment transport over a transverse cross section vanishes and is defined for a variable-width, constantdepth model as follows:

$$
\int_{-H}^{0} \int_{-b / 2}^{b / 2}\left\{u C-K_{h} \frac{\partial C}{\partial x}\right\} d y d z=0
$$

where the first term in brackets $(u C)$ is advective flux and the second term is dispersive flux.

The model is closed by defining the total mass of SSC over the entire model domain,

$$
c_{*} H L\langle b\rangle=\int_{-H}^{0} \int_{-b / 2}^{b / 2} \int_{0}^{L} C(x, z) b(x) d x d y d z
$$

where $\langle b\rangle$ is the average width; $L$ is the length of the

\begin{tabular}{|c|c|c|c|c|c|c|c|c|c|c|}
\hline$Q\left(\mathrm{~m}^{3} \mathrm{~s}^{-1}\right)$ & -10 & -20 & -40 & -60 & -80 & -100 & -160 & -240 & -320 & -600 \\
\hline$x_{L}\left(10^{3} \mathrm{~m}\right)$ & 15.7 & 14.2 & 12.7 & 12 & 11.5 & 11 & 10.3 & 9.7 & 9.3 & 8.4 \\
\hline$x_{c}\left(10^{3} \mathrm{~m}\right)$ & 47.9 & 43.1 & 38.7 & 36.4 & 34.9 & 33.7 & 31.4 & 29.5 & 28.2 & 25.6 \\
\hline $\mathrm{d} s / \mathrm{d} x_{\max }$ & 0.0095 & 0.0011 & 0.0012 & 0.00125 & 0.0013 & 0.00135 & 0.00145 & 0.00155 & 0.0016 & 0.0018 \\
\hline$X_{2}\left(10^{3} \mathrm{~m}\right)$ & 67.1 & 60.4 & 54.3 & 51.1 & 48.9 & 44.0 & 41.3 & 39.6 & 39.6 & 36.0 \\
\hline
\end{tabular}
model domain, and the user-defined parameter $c_{*}$ is the

Table 1 Variation of salinity parameters $x_{L}$ (length scale of salinity variation), $x_{c}$ (location of maximum gradient), the maximum magnitude of the salinity gradient $\mathrm{d} s / \mathrm{d} x_{\max }$, and the position of the 2 psu isohaline $X_{2}$ as a function of freshwater discharge $Q$

These results are found from an equilibrium fit to available long-term data, using the method described in Monismith et al. (2002). Units of length are in $10^{3} \mathrm{~m}$ 
average SSC over the model domain. For a given average concentration $c_{*}$, the morphodynamic equilibrium (Eq. 6) is solved analytically, using Eqs. 1, 4, and 5, to define the equilibrium distribution of SSC:

$$
\begin{aligned}
& C(x, z)=A_{1} \underbrace{}_{\text {longitudinal component } \underbrace{\exp (F(x))}_{\text {vertical component }} \exp \left\{\frac{-w_{s}}{K_{v}}(z+H)\right\}}, \quad(8 \mathrm{a}) \\
& F(x)=\underbrace{\frac{-T_{s} g \beta H^{3} s(x)}{48 \rho_{o} A_{v} T_{K} K_{h}}}_{\text {baroclinic component }}-\underbrace{\frac{T_{T} g H^{3} c_{b}(x)}{48 \rho_{o} A_{v} T_{K} K_{h}}}_{\mathrm{SSC} \text { component }}+\underbrace{\frac{3 T_{Q} Q L_{e}}{2 H T_{K} K_{H} b(x)}}_{\text {freshwater component }},
\end{aligned}
$$

where $T_{S}, T_{Q}, T_{T}$, and $T_{K}$ are parameters that are defined in the "Appendix." The longitudinal distributions of salinity, SSC, and freshwater discharge all contribute to the equilibrium distribution of sediment. The definition of $c_{*}$ is used to find the constant $A_{1}$ :

$$
A_{1}=\frac{c_{*} P e_{v} L<b>}{\left(1-\exp \left\{-P e_{v}\right\}\right) \int_{0}^{L} b(x) \exp \{F(x)\} d x} \text {. }
$$

Equations 8a, 8b, and 9 are solved iteratively, as described in Supplement S.1.

\section{Oxygen Consumption by Suspended Sediment Oxygen Demand}

In typical rivers and estuaries, the depletion of oxygen occurs from the consumption of organic material and is expressed as biological oxygen demand (BOD), sediment oxygen demand at the consolidated bed (SOD), chemical oxygen demand, and nitrogen oxygen demand (NBOD; Cox 2003). BOD occurs on individual molecules, colloidal material, and on detritus associated with suspended sediment aggregates in the water column. Here, we focus on oxygen depletion due to sediment-linked biological material that is trapped at the estuarine turbidity maximum. Measurements show that the organic content of SSC in the Ems ranges from $10 \%$ to $20 \%$ and consists of refractory (relatively "old") material with a slow degradation rate and rate of oxygen consumption (personal communication, A. Scholl; Wurpts and Torn 2005). However, because nearbottom SSCs exceed $50 \mathrm{~kg} \mathrm{~m}^{-3}$ (see Figs. 3 and 4), the total organic material and oxygen demand is capable of depleting oxygen. To gain better understanding of the effect of elevated concentrations of organic material on DO concentrations, we explicitly neglect the oxygen depleted by NBOD. Similarly, we neglect oxygen added by algal production and consumed through respiration, since high turbidity severely limits light and algal growth (Colijn 1982; May et al. 2003). These processes are left for future study.

To model the depletion of oxygen $\left(\mathrm{O}_{2}\right)$ due to organic material in the water column, we assume that the oxygen consumption within a control volume is proportional to the concentration of organic material, which in turn is proportional to SSC. This rate of change is modified by a factor of $\mathrm{O}_{2} /\left(k_{m}+\mathrm{O}_{2}\right)$, where $k_{m}$ is a constant which is typically set equal to $0.7 \times 10^{-3} \mathrm{~kg} \mathrm{~m}^{-3}$ (Cox 2003). This factor ensures that the rate of oxygen consumption goes to zero in the limit of zero oxygen concentration. Hence, we define the suspended sediment oxygen demand to be

$\mathrm{SSOD}=\frac{-\mathrm{O}_{2}}{k_{m}+\mathrm{O}_{2}} p k_{r}(T) C(x, z)$,

where $p$ is the percent organic material in the SSC and is set to 0.1 , and $k_{r}\left[\mathrm{~s}^{-1}\right]$ is a (positive) rate of decay of organic (carbonaceous) material that varies with temperature $T$. The temperature dependence is based on the Arrhenius relation and is commonly modeled as $k_{r}(T)=k_{r e f} \theta^{1 / T_{o}\left(T-T_{r e f}\right)}$, where $\theta$ is a parameter which ranges from 1.04 to 1.13 ; $T_{\text {ref }}$ is a reference temperature of $20^{\circ} \mathrm{C}$, and $T_{o}=1^{\circ} \mathrm{C}$ is a dummy variable applied to retain nondimensionality (see Cox 2003). Reported values for the organic material decay coefficient (carbonaceous oxygen demand) at $20^{\circ} \mathrm{C}, k_{\text {ref }}$, range from $\sim 10^{-7} \mathrm{~s}^{-1}$ to $2.3 \times 10^{-5} \mathrm{~s}^{-1}$ or 0.01 day $^{-1}$ to 2.0 day $^{-1}$ (Cox 2003). We use a value of $k_{\text {ref }}$ that is an order of magnitude smaller (1.3 $\left.10^{-8} \mathrm{~s}^{-1}\right)$, as described in "Model Calibration and Validation" (see Table 2). To maintain consistency in the units, we express oxygen $\mathrm{O}_{2}$ in units of kilogram per cubic meter in the model; in the results section, we convert $\mathrm{O}_{2}$ to the more commonly reported units of milligram per liter.
Table 2 Standard parameters prescribed in the vertical model of oxygen depletion (Model Calibration and Validation): $K_{v}=$ eddy diffusivity, $H=$ depth, $w_{\mathrm{s}}=$ settling velocity, $k_{L}=$ aeration coefficient, $S_{\mathrm{b}}=$ bottom oxygen demand, $k_{r}=$ oxygen demand due to SSC, $p=$ proportion of $\mathrm{SSC}$ that is organic matter, $T=$ water temperature

\begin{tabular}{lcccccrrr}
\hline & $K_{v}\left(\mathrm{~m}^{2} \mathrm{~s}^{-1}\right)$ & $H(\mathrm{~m})$ & $w_{\mathrm{s}}\left(\mathrm{ms}^{-1}\right)$ & $k_{L}\left(\mathrm{~ms}^{-1}\right)$ & $S_{\mathrm{b}}\left(\mathrm{kg} \mathrm{O}_{2} \mathrm{~m}^{-2} \mathrm{~s}^{-1}\right)$ & $k_{r e f}\left(\mathrm{~s}^{-1}\right)$ & $p(-)$ & $T\left({ }^{\circ} \mathrm{C}\right)$ \\
\hline "Local fit" & 0.001 & 7 & 0.001 & $10^{-5}$ & $5 \times 10^{-8}$ & $8 \times 10^{-9}$ & 0.1 & 20 \\
"Estuary fit" & 0.001 & 7 & 0.001 & $10^{-5}$ & $3 \times 10^{-8}$ & $1.3 \times 10^{-8}$ & 0.1 & 20 \\
\hline
\end{tabular}


Next, we apply the control volume approach to oxygen fluxes in the model estuary, applying the assumption that horizontal velocity $u$, vertical velocity $w, \mathrm{O}_{2}$, longitudinal dispersion $K_{h}$, and eddy diffusivity $K_{v}$ are uniform over the width. The kinematic conditions for velocity are applied at the side walls $(y= \pm b / 2)$, and no normal flux of oxygen is assumed through these boundaries. Assuming steady conditions and integrating over width, the mass balance of $\mathrm{O}_{2}$ becomes

$$
\begin{aligned}
\mathrm{O}= & \frac{\partial}{\partial x}\left(b u \mathrm{O}_{2}\right)-\frac{\partial}{\partial z}\left(b w \mathrm{O}_{2}\right)+\frac{\partial}{\partial x}\left(b K_{h} \frac{\partial \mathrm{O}_{2}}{\partial x}\right)+\frac{\partial}{\partial z} \\
& \times\left(b K_{v} \frac{\partial \mathrm{O}_{2}}{\partial z}\right)-b \frac{\mathrm{O}_{2}}{k_{m}+\mathrm{O}_{2}} p k_{r} C .
\end{aligned}
$$

The first two terms on the right-hand side are the convergence of width-integrated advective flux of DO; the third and fourth terms are the convergence of widthintegrated diffusive flux of DO, and the last term is the sink of DO. We simplify using the continuity equation (mass balance of water),

$0=\frac{\partial}{\partial x}(b u)+\frac{\partial}{\partial z}(b w)$

which yields the following equation for $\mathrm{O}_{2}(x, z)$,

$0=\underbrace{-u \frac{\partial \mathrm{O}_{2}}{\partial x}-w \frac{\partial \mathrm{O}_{2}}{\partial z}}_{\text {advection }} \underbrace{-\frac{K_{h}}{L_{e}} \frac{\partial \mathrm{O}_{2}}{\partial x}+K_{v} \frac{\partial^{2} \mathrm{O}_{2}}{\partial z^{2}}+K_{h} \frac{\partial^{2} \mathrm{O}_{2}}{\partial x^{2}}}_{\text {diffusion }} \underbrace{-\frac{\mathrm{O}_{2}}{k_{m}+\mathrm{O}_{2}} p k_{r} C}_{\text {sink }}$.

The vertical velocity, $w$, is found from continuity (Eq. 12), using Eq. 1 and the solution from Eq. 5. The term $-\frac{K_{h}}{L_{e}} \frac{\partial \mathrm{O}_{2}}{\partial x}$ arises from the transport caused by the width convergence of the estuary; for channels ( $L_{e}$ large), this term becomes negligible. Because sediment concentration $C(x, z)$ and the velocity $u(x, z)$ are known by Eqs. $8 \mathrm{a}, 8 \mathrm{~b}$, and 5 , respectively, only DO concentrations are unknown and must be solved for using the appropriate boundary conditions. At the consolidated bed, we assume that oxygen is consumed by the SOD at the rate $S_{b}(T)\left(\mathrm{kg} \mathrm{O}_{2} \mathrm{~m}^{-2} \mathrm{~s}^{-1}\right)$,

$\left.K_{v} \frac{\partial \mathrm{O}_{2}}{\partial z}\right|_{z=-H}=\left.\frac{\mathrm{O}_{2}}{k_{m}+\mathrm{O}_{2}} S_{b}(T)\right|_{z=-H}$

In analogy with oxygen demand in the water column (Eq. 10), we model the effect of temperature as $S_{b}(T)=S_{b r} \theta^{1 / T_{o}\left(T-T_{r e f}\right)}$, where $S_{b r}$ is a constant at the reference temperature of $20^{\circ} \mathrm{C}$, and add the corrective factor $\mathrm{O}_{2} /\left(k_{m}+\mathrm{O}_{2}\right)$ to ensure that negative DO concentrations cannot occur. Typical river and estuary values of $S_{b r}$ range from $\sim 10^{-9} \mathrm{~kg} \mathrm{O}_{2} \mathrm{~m}^{-2} \mathrm{~s}^{-1}$ (sandy or mineral bed) to $10^{-7} \mathrm{~kg}$
$\mathrm{O}_{2} \mathrm{~m}^{-2} \mathrm{~s}^{-1}$ (organic deposits), with typical estuarine values of $\sim 1$ to $2 \times 10^{-8} \mathrm{~kg} \mathrm{O}_{2} \mathrm{~m}^{-2} \mathrm{~s}^{-1}$ (Chapra 1997). In the muddy Seine estuary, measurements by Garban et al. 1995 reported an SOD value of $3.2 \times 10^{-8} \mathrm{~kg} \mathrm{O}_{2} \mathrm{~m}^{-2} \mathrm{~s}^{-1}$, with a range of $1.7 \times 10^{-8} \mathrm{~kg} \mathrm{O}_{2} \mathrm{~m}^{-2} \mathrm{~s}^{-1}$ to $8.3 \times 10^{-8} \mathrm{~kg} \mathrm{O}_{2} \mathrm{~m}^{-2} \mathrm{~s}^{-1}$. We calibrate our model using these reported ranges of SOD in "Model Calibration and Validation." At the surface, the flux of oxygen between the atmosphere and the water column is proportional to the difference between saturated conditions $\left(\mathrm{O}_{2, \mathrm{sat}}\right)$ and actual conditions $\left(\left.\mathrm{O}_{2}\right|_{z=0}\right)$ :

$\left.K_{v} \frac{\partial \mathrm{O}_{2}}{\partial z}\right|_{z=0}=k_{L}\left(\mathrm{O}_{2, s a t}-\left.\mathrm{O}_{2}\right|_{z=0}\right)$

where $k_{L}\left(\mathrm{~m} \mathrm{~s}^{-1}\right)$ is an empirical constant that depends on climatic conditions, depth, and hydrodynamic conditions (see, e.g., Cox 2003). The flux of oxygen at the surface is often assumed to be a constant on the order of $10^{-8} \mathrm{~kg} \mathrm{O}_{2} \mathrm{~m}^{-2} \mathrm{~s}^{-1}$ (Lin et al. 2006). Here, we allow the flux to vary based on the oxygen deficit at the surface. In the Seine River, Garnier et al. (2001) found values of the aeration coefficient $k_{L}$ along different reaches to be between 0 and $0.07 \mathrm{~m} \mathrm{~h}^{-1}$, with averages between 0.02 and $0.07 \mathrm{~m} \mathrm{~h}^{-1}\left(5 \times 10^{-6} \mathrm{~m} \mathrm{~s}^{-1}\right.$ to $2 \times$ $10^{-5} \mathrm{~m} \mathrm{~s}^{-1}$ ). Cox (2003) lists multiple studies with depthaveraged values of the aeration coefficient that vary between 0 and 250 day $^{-1}$ with an order of magnitude of $\sim 0.4$ day $^{-1}$ for large rivers, or, when scaled by a depth of $H=7 \mathrm{~m}$, approximately $3 \times 10^{-5} \mathrm{~m} \mathrm{~s}^{-1}$. The saturated oxygen concentration is a function of temperature and salinity and is $\sim 8.5 \mathrm{mg}^{-1}$ at $20^{\circ} \mathrm{C}$ (APHA 1992). The downstream and upstream boundary condition $(x=0$ and $x=L)$ is found from the modeled SSC at the boundary, using the simplified 1D DO model described below. The 2D model is solved using an implicit finite difference algorithm with 100 alongchannel grid points and 30 vertical grid points.

To gain fundamental understanding of DO depletion and to obtain an upstream and downstream boundary condition, we simplify Eq. 13 by assuming that horizontal advection and dispersion terms are negligible, to first order (i.e., terms 1,3 , and 5 can be neglected). When applied as a boundary condition, the appropriateness of this assumption must be checked against results. Also assuming negligible vertical velocities, the simplified $1 \mathrm{D}$ model requires that

$0=K_{v} \frac{\mathrm{d}^{2} \mathrm{O}_{2}}{\mathrm{~d} z^{2}}-\frac{\mathrm{O}_{2}}{k_{m}+\mathrm{O}_{2}} p k_{r} C(z)$

This equation is solved numerically using the boundary conditions described in Eqs. 14 and 15. The vertical variation of $\mathrm{SSC}, C(z)$, is prescribed by the parameter $c *$ (Eq. 7), which in this case reduces to the depth-averaged SSC. For clarity, we denote this depth-averaged SSC by $c_{*} d$ and reserve $c_{*}$ for the estuary-averaged SSC. 
Equation 16 is further simplified by assuming that the term $\frac{\mathrm{O}_{2}}{k_{m}+\mathrm{O}_{2}} \sim 1$, which is approximately valid for DO concentrations above $2-3 \times 10^{-3} \mathrm{~kg} \mathrm{~m}^{-3}\left(2-3 \mathrm{mg} \mathrm{l}^{-1}\right)$. Applying boundary conditions, we find the following analytical solution:

$$
\begin{aligned}
\mathrm{O}_{2} & =\mathrm{O}_{2, s a t}-S_{b}\left(\frac{-z}{K_{v}}+\frac{1}{k_{L}}\right) \\
& +\frac{p k_{r} c_{* d} H / w_{s}}{\left(1-\exp \left(-P e_{v}\right)\right)}\left\{\left(\frac{w_{s}}{k_{L}}-1\right) \exp \left(-P e_{v}\right)+\exp \left(\frac{-w_{s}}{K_{v}}(z+H)\right)+\frac{w_{s}}{K_{v}} z-\frac{w_{s}}{k_{L}}\right\}
\end{aligned}
$$

To explore this expression, we simplify it by noting that for the typical values of depth $H$, settling velocity $w_{s}$, and eddy diffusivity $K_{v}$ in an estuary, the sediment Peclet number $P e_{v}=w_{s} H / K_{v}$ is much larger than one; physically, this simply means that most SSC is concentrated near the bed rather than distributed through the water column. Using the resulting simplification that $\exp \left(-P e_{v}\right) \sim 0$, we find that oxygen concentration at the surface $(z=0)$ and at the bed $(z=-H)$ can be approximated as

$$
\begin{aligned}
& \mathrm{O}_{2}(z=0) \approx \mathrm{O}_{2, s a t}-\frac{S_{b}+p k_{r} c_{* d} H}{k_{L}} \\
& \mathrm{O}_{2}(z=-H) \approx \mathrm{O}_{2, \text { sat }}-\frac{S_{b}}{k_{L}}\left(\frac{H k_{L}}{K_{v}}+1\right)-\frac{p k_{r} c_{* d} H}{k_{L}} \\
& \times\left\{\frac{-k_{L}}{w_{s}}+\frac{H k_{L}}{K_{v}}+1\right\} .
\end{aligned}
$$

These functions suggest that, for DO above 2 to $3 \times 10^{-3} \mathrm{~kg}$ $\mathrm{m}^{-3}\left(2-3 \mathrm{mg} \mathrm{l}^{-1}\right)$, oxygen depletion near the surface is a linear function of the organic matter (carbonaceous) decay parameter $k_{r}$, the average concentration of SSC in the vertical $(c * d)$, the depth $H$, and the sediment oxygen demand $S_{b}$ and is inversely proportional to aeration. Near the bed, additional parameters such as eddy diffusivity and settling velocity contribute to DO concentrations in the nondimensional terms $\frac{H k_{L}}{K_{v}}$ and $\frac{-k_{L}}{w_{s}}$ and account for water column variation.

\section{Model Results}

The model presented in "Model" depends both on vertical water column processes (mixing, aeration, etc.) and on the longitudinal structure of SSC and circulation. We first calibrate and validate the model by comparing point measurements of SSC and DO using the vertical water column model described in Eq. 16 ("Model Calibration and Validation"), then address the effect of circulation on the distribution of SSC and DO concentration ("Estuarine Model").

\section{Model Calibration and Validation}

We test and calibrate our DO model by comparing model results (using the simplified, 1D vertical depletion model, Eq. 16) with the measured dependence of DO on SSC at three fixed stations in 2005 and 2006 (Fig. 7). These upstream stations, located between $\mathrm{km} 72.6$ and 86.9, are within the summertime turbidity zone measured in Figs. 2 and 3 and record the largest SSCs within the estuary (greater than 25 and $50 \mathrm{~kg} \mathrm{~m}^{-3}$, the measurement limits). The large SSC measurement range allows for comparison with the model over a large range of DO. To compare with measurements, the modeled SSC (which uses the vertically averaged SSC, $c_{*}{ }$, as an input) is converted to an equivalent point measurement at the sensor depths using the default values of settling velocity, eddy diffusivity, and water depth (see Eq. 4 and Table 2). The sensor depths are located $\sim 2,1.5$, and $1.5 \mathrm{~m}$ above the bed for Figs. $7 \mathrm{a}-\mathrm{c}$, respectively. To obtain appropriate model parameters, we next vary the aeration parameter $k_{L}$ and the bottom sediment oxygen demand $S_{b}$ within the range reported in the literature (see Eqs. 14 and 15). The carbonaceous decay parameter $k_{r}$ (see Eq. 10), which is less well established for estuarine conditions, is allowed to float. Physical parameters such as eddy diffusivity and settling velocity are held fixed to remain consistent with the assumptions of the estuarine model. To reduce the effect of temperature, only DO concentrations measured within a small band between $18^{\circ} \mathrm{C}$ and $21^{\circ} \mathrm{C}$ are considered (the model temperature is $20^{\circ} \mathrm{C}$ ). The envelope around the mean measured DO indicates the standard deviation.

Two fits of the 1D model are shown in Fig. 7 (see Table 2 for parameter values) and are labeled "local fit" and "estuary fit." Measurements and both fits show initially steep declines with SSC which level out as DO approaches hypoxic conditions $\left(\mathrm{DO}<2 \mathrm{mg} \mathrm{l}^{-1}\right)$. Over much of the measured range, both model estimates are within the average standard deviation of $1 \mathrm{mg} \mathrm{^{-1 }}$ for the measurement, and the overall root mean square (rms) difference is $0.5 \mathrm{mg} \mathrm{l}^{-1}$ for the "local fit" and $0.8 \mathrm{mg}^{-1}$ for the "estuary fit." Hence, to first order, both fits model the observed variation of DO with SSC. Some divergence between measurements and the "estuary fit" occurs at zero SSC ( $y$ intercept in Fig. 7), with the "estuary fit" overpredicting the measured DO by 1 to $2 \mathrm{mg} \mathrm{l}^{-1}$ in Figs. 7b, c. Compared to the "local fit," however, the "estuary fit" better represents the summertime DO data at zero SSC for Figs. 4a, 5a, and $7 \mathrm{a}$, which are $\sim 5.5, \sim 7.5$, and $\sim 5.5 \mathrm{mg} \mathrm{l}^{-1}$, respectively. Thus, the "estuary fit" better represents the average oxygen demanded (by SOD) over the estuary when SSCs are small.

The sediment oxygen demand and aeration in the "estuary fit," $S_{b}=3.0 \times 10^{-8} \mathrm{~kg} \mathrm{O}_{2} \mathrm{~m}^{-2} \mathrm{~s}^{-1}$ and $k_{L}=10^{-5} \mathrm{~m} \mathrm{~s}^{-1}$, closely echo values from the muddy Seine estuary measured by 
Fig. 7 Measured average DO as a function of measured SSC at three stations along the Ems for the temperature range $18^{\circ} \mathrm{C}$ to $21^{\circ} \mathrm{C}$ for data from 2005 to 2006, compared with 1D model results. The standard deviation of the measurement is shown by the envelope around the mean. Two-parameter fits are depicted: a "local" fit that minimizes error in Weener (b) and Leerort (c), and an "estuary fit" that better represents average DO over the estuary in the limit of zero SSC

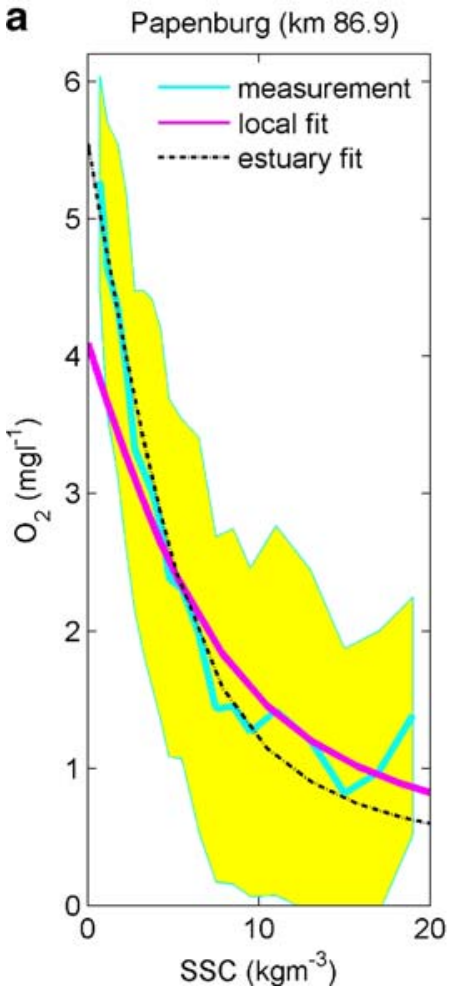

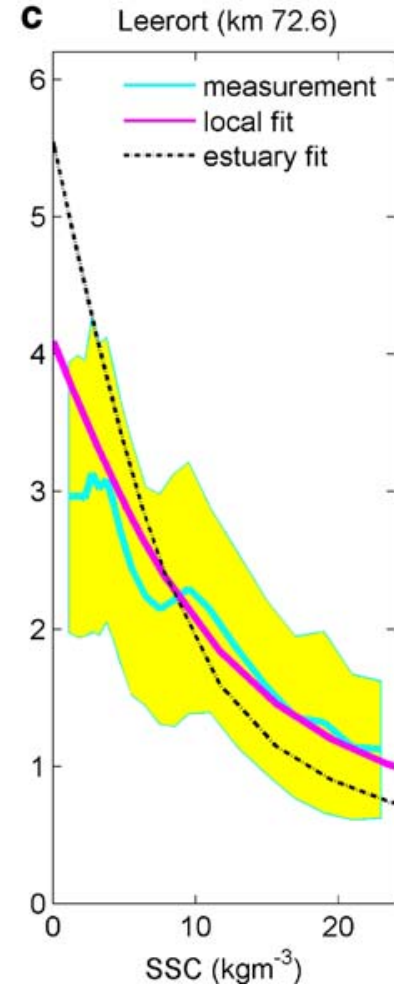

Garban et al. (1995; mean $\left.S_{b}=3.2 \times 10^{-8} \mathrm{~kg} \mathrm{O}_{2} \mathrm{~m}^{-2} \mathrm{~s}^{-1}\right)$ and Garnier et al. (2001) $\left(5 \times 10^{-6} \mathrm{~m} \mathrm{~s}^{-1}<k_{L}<2 \times 10^{-5} \mathrm{~m} \mathrm{~s}^{-1}\right)$. Both estimates of the organic material decay rate are an order of magnitude smaller than reported values of carbonaceous decay $\left(10^{-7} \mathrm{~s}^{-1} \mathrm{Cox} 2003\right)$ and confirm that

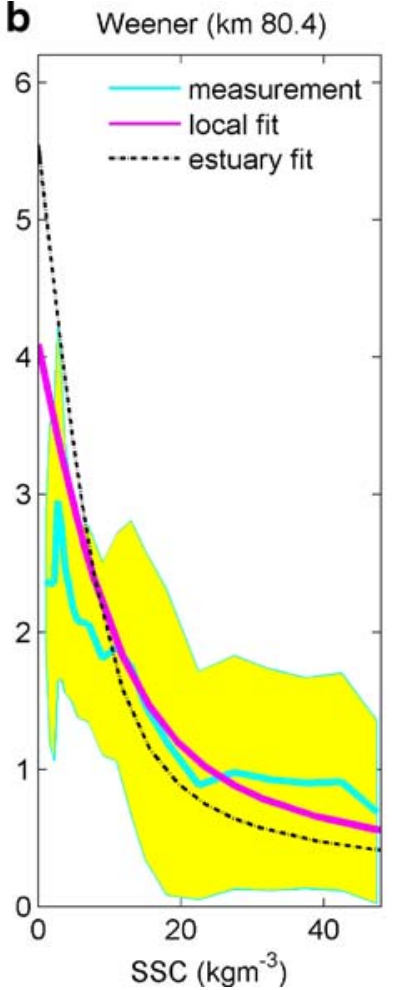

Fig. 8 Variation in measured DO as a function of temperature, compared with 1D model results. A scatter plot of measurements shows total variation of data from 2005 to 2006 Saturated conditions are shown by a solid black line. "LowSSC" and "high-SSC" measurements correspond to average DO from SSC bins of $0-1$ and $18-25 \mathrm{~kg} \mathrm{~m}^{-3}$, respectively. "Low-SSC model" and "highSSC model" correspond to a modeled SSC of 0.5 and $20 \mathrm{~kg} \mathrm{~m}^{-3}$ at the measurement heights of $2,1.5$, and $1.5 \mathrm{~m}$ for $\mathbf{a}$, $\mathbf{b}$, and $\mathbf{c}$, respectively. The parameters corresponding to the local fit to the turbid zone were used, and a temperature adjustment coefficient of $\theta=1.1$ was used

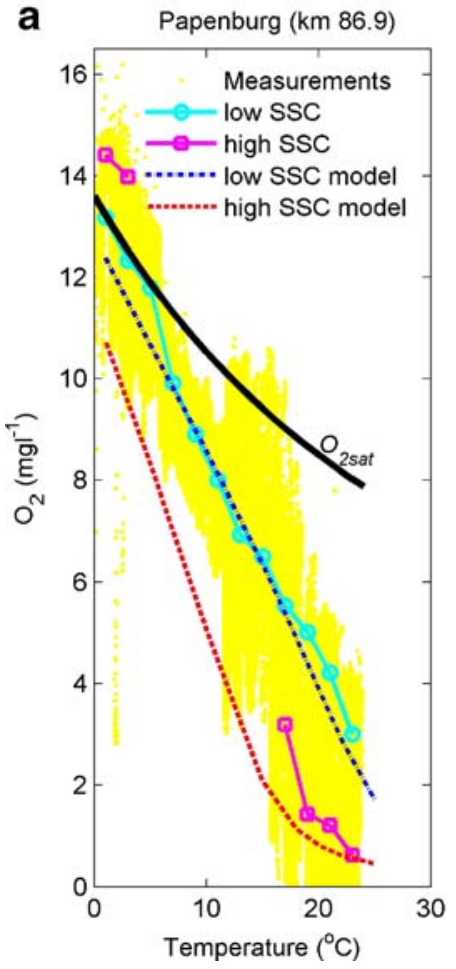

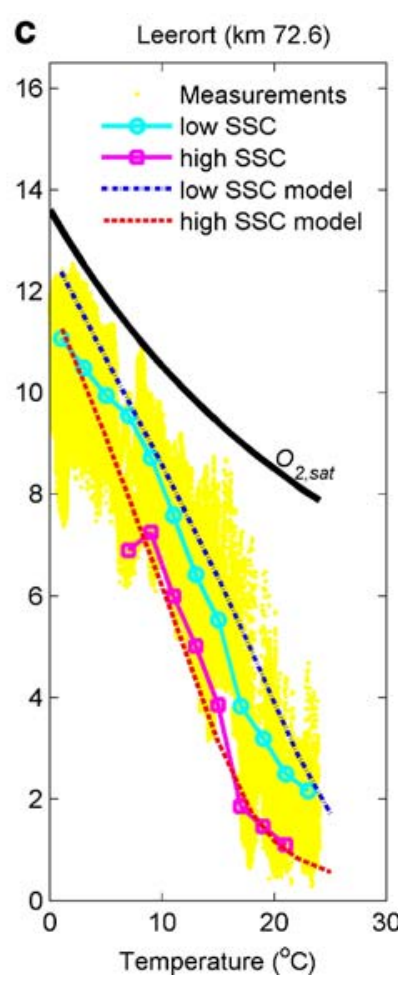

the organic material attached to SSC is extremely refractory (see also van Es et al. 1980; Baretta and Ruardij 1988).

The simplified analytical solutions of DO (Eqs. 18 and 19) help explain differences between the measurement sites and models. During clear conditions (zero SSC), the

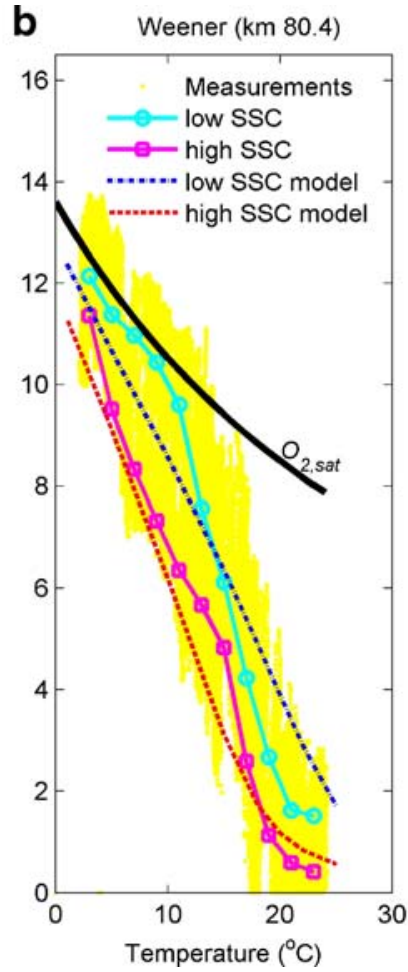


oxygen depletion is set by a balance between SOD and aeration, i.e., $S_{b} / k_{L}$ (see Eq. 18). Hence, the measurement sites in Figs. 7b, c may have less aeration, or greater SOD, than the site in Fig. 7a. Similarly, the slope of DO versus SSC is set by the ratio of organic material decay to aeration, i.e., $k_{r} / k_{L}$ (see Eq. 18). Hence, the sites in Fig. 7b, c, which have slightly less slopes of DO vs SSC than Fig. 7a, may be exposed to more refractory material (higher $k_{r}$ ) or reduced aeration. By contrast, the DO depletion slope in Terborg,

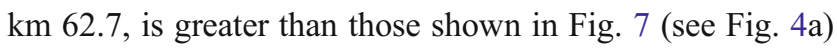
and suggests reduced aeration or higher degradation rates of organic material. These considerations show that the assumption of constant conditions may oversimplify the estuarine model. However, bathymetry, tidal mixing and transport, lateral circulation, and other factors may also affect the measured DO and SSC concentrations, and it is beyond the scope of this contribution to fully consider these factors. Nonetheless, the fit of the model to measurement data (Fig. 7) confirms that that the constant parameter values reasonably model the bulk oxygen depletion occurring due to SOD and SSC over a large portion of the turbid zone.

The skill of the model in predicting oxygen depletion as a function of temperature is presented in Fig. 8 for both low SSCs $\left(0-1 \mathrm{~kg} \mathrm{~m}^{-3}\right)$ and elevated SSCs $\left(18-25 \mathrm{~kg} \mathrm{~m}^{-3}\right)$ at three locations (Papenburg, km 86.9; Weener, km 80.1; and Leerort, $\mathrm{km}$ 72.6). The measured DO at both low and high SSC is binned into $2^{\circ} \mathrm{C}$ intervals, and the average is compared against modeled results. The "local fit" to the ETZ is used for the model (see Table 2), and the average SSC over the water column, $c_{*}$, is adjusted to produce an $\mathrm{SSC}$ of $20 \mathrm{~kg} \mathrm{~m}^{-3}$ at the measurement heights. We find that the parameter $\theta$, used to adjust the DO depletion rates $k_{r}$ and $S_{b}$ as a function of temperature (see Eqs. 10 and 14), best reproduces measured results with a value of $\theta \sim 1.1$.

Overall, the measured and modeled variation of DO with temperature agrees to within an rms difference of $\sim 1 \mathrm{mg}^{-1}$, with both depicting a nearly linear increase in DO as water becomes colder (Fig. 8). Moreover, the model results move closer to saturated conditions as temperature falls and oxygen demand decreases, reflecting the same observation in the measured data. Elevated SSC conditions, labeled "high SSC," are typically $\sim 1-3 \mathrm{mg}^{-1}$ less than low-SSC conditions in both model and measurements, though some scatter occurs in the data. During warmer (summertime) conditions, DO concentrations approach zero and the observed variation with temperature asymptotes in both the modeled and measured results. Model and measurements of high SSC do not agree well below $T=19^{\circ} \mathrm{C}$ in Papenburg (Fig. 8a), perhaps because of a paucity of highSSC data at lower temperatures. In Leerort (Fig. 8c), modeled DO slightly overpredicts measurements for lowSSC conditions. Besides the processes discussed for Fig. 7, other sources of variation between the model and measurements include variations in decay rates not captured by $\theta$ and the supersaturated DO conditions that are observed to occur periodically at low SSC. Overall, however, the bulk characteristics of the measured and modeled temperature variation agree and further validate the DO model.

\section{Estuarine Model}

Next, we analyze the patterns of circulation, SSC, and DO concentrations that result in a model 2D estuary from changing freshwater discharge, depth, and mixing. Unless otherwise stated, all parameters are held to the "estuary fit" parameters displayed in Tables 2 and 3 (SSC model parameters). The hydrodynamic variables in Table 3 represent low-freshwater-discharge conditions that occur during the summer months in the Ems estuary (see Talke et al. 2009 for discussion). Parameter studies of settling velocity, horizontal dispersion, width variation, total sediment supply, and longitudinal salinity structure are described in Supplement S.3.

Figure 9 shows examples of circulation, SSC, and DO concentrations that occur when standard parameters are used (Fig. 9b, d, f) and when one parameter, depth, is reduced from $H=7 \mathrm{~m}$ to $H=5 \mathrm{~m}$ (Fig. 9a, c, e). The model estimates for SSC and DO in the $H=7 \mathrm{~m}$ case (standard parameters) qualitatively reproduce the field conditions observed in Figs. 2 and 3. In both model and measurements, near-bed SSCs with magnitudes greater than $10 \mathrm{~kg} \mathrm{~m}^{-3}$ cover the bottom to depths of 1 to $2 \mathrm{~m}$ from the salt wedge to the tidal weir at $\mathrm{km} 100$ and produce a zone of depleted DO that coincides with elevated SSC. The

Table 3 Standard parameters used to calculate circulation and the equilibrium distribution of sediment in the 2D model

\begin{tabular}{|c|c|c|c|c|c|c|c|c|c|}
\hline$S_{o}(\mathrm{psu})$ & $x_{L}(\mathrm{~m})$ & $x_{c}(\mathrm{~m})$ & $A_{v}\left(\mathrm{~m}^{2} \mathrm{~s}^{-1}\right)$ & $\mathrm{L}(\mathrm{m})$ & $Q\left(\mathrm{~m}^{3} \mathrm{~s}^{-1}\right)$ & $K_{h}\left(\mathrm{~m}^{2} \mathrm{~s}^{-1}\right)$ & $c *\left(\mathrm{~kg} \mathrm{~m}^{-3}\right)$ & $L_{e}(\mathrm{~m})$ & $B_{o}(\mathrm{~m})$ \\
\hline 30 & $14 \times 10^{3}$ & $43 \times 10^{3}$ & 0.001 & $100 \times 10^{3}$ & -10 & 100 & 0.5 & $20 \times 10^{3}$ & $8 \times 10^{3}$ \\
\hline
\end{tabular}

The standard depth $H$, settling velocity $w_{\mathrm{s}}$, and eddy diffusivity $K_{v}$ are described in Table 2, as are the additional parameters needed for the oxygen model $-k_{L}, k_{r}, p$, and $S_{\mathrm{b}}$. Here, $S_{*}$ is the salinity at the seaward boundary; $x_{L}$ scales the salinity gradient; $x_{c}$ is the location of the maximum salinity gradient relative to the seaward boundary, $A_{v}=$ eddy viscosity, $L=$ length of model domain, $Q=$ freshwater discharge, $K_{\mathrm{h}}=$ horizontal dispersion coefficient, $c_{*}$ is the average SSC over the estuary; $L_{e}$ is the convergence length scale; and $B_{o}$ is the width at the estuarine mouth. Note that discharge $Q$ is negative in our coordinate system 
Fig. 9 a-f Variation in modeled circulation (top panels), SSC (middle panels), and dissolved oxygen concentrations (bottom panels) when changing depth from $5 \mathrm{~m}$ (left panels) to $7 \mathrm{~m}$ (right panels). All other parameters are set to the standard values in Table 2
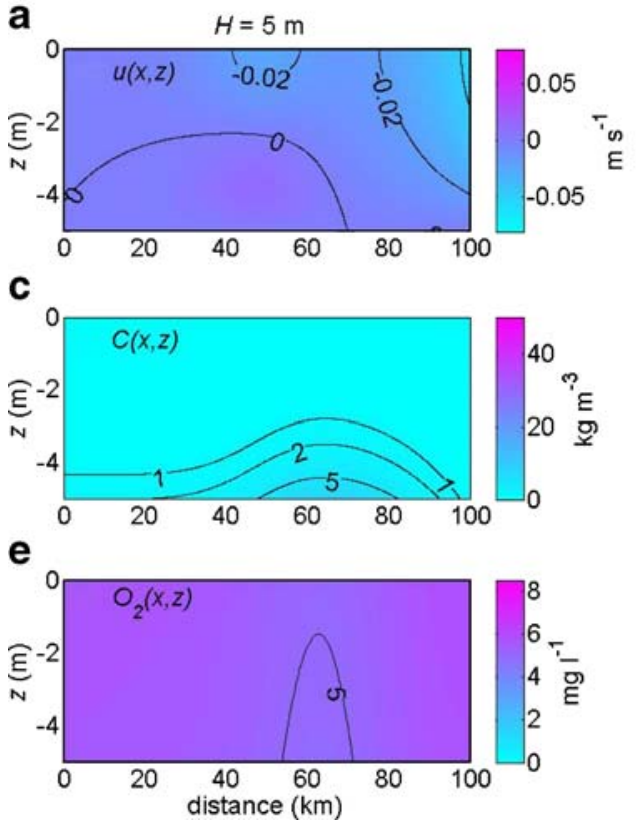

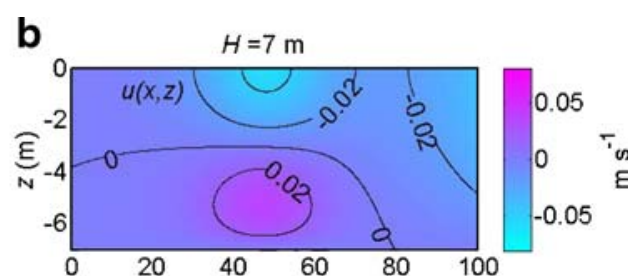

d
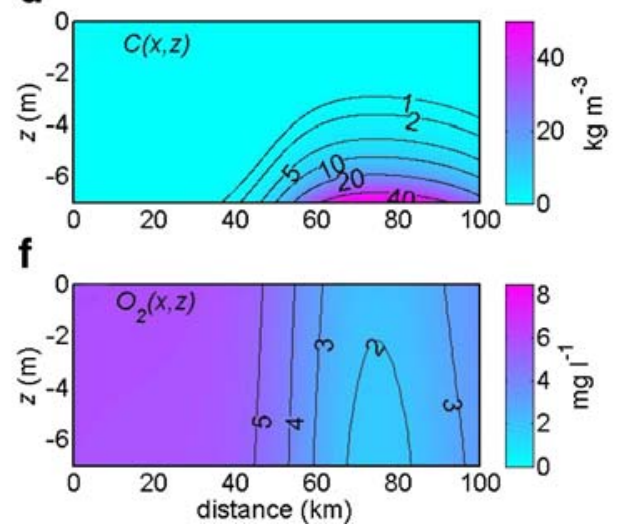

maximum SSC in each occurs between $\mathrm{km} 70$ and 80 (Figs. 2, 3, and 9). Compared to experimental results (Figs. 2 and 3), the length scale of the modeled turbid zone (Fig. 9) is larger; the DO minimum is $\sim 0.8 \mathrm{mg} \mathrm{l}^{-1}$ greater (perhaps because model temperature is less), and the topbottom differences in DO concentrations are less. Nonetheless, the overall agreement of the macroscopic (zeroth order) trends confirms that we can use our idealized model to investigate the underlying physical processes and resulting DO concentrations.

A strongly nonlinear response in DO and SSC is observed as $H$ is altered from 5 to $7 \mathrm{~m}$; near-bed circulation increases from a maximum of $\sim 0.01$ to $\sim 0.03 \mathrm{~m} \mathrm{~s}^{-1}$; the maximum SSC is amplified from $\sim 9$ to $\sim 60 \mathrm{~kg} \mathrm{~m}^{-3}$, and the DO concentrations are reduced to nearly hypoxic (just over $2 \mathrm{mg} \mathrm{1}^{-1}$ ). The observed changes are driven by the nonlinear amplification of baroclinic circulation, which is proportional to $H^{3}$ and thus increases by a factor of 2.5 (see Eq. 5). By contrast, the magnitude of circulation caused by freshwater discharge is reduced between 5 and $7 \mathrm{~m}$ since the same inflow $Q$ of $-10 \mathrm{~m}^{3} \mathrm{~s}^{-1}$ is distributed over a greater cross-sectional area. Hence, the downstream penetration of the $-0.05-\mathrm{m} \mathrm{s}^{-1}$ velocity contour from the upstream boundary is greatly reduced for $H=7 \mathrm{~m}$.

The enhanced near-bed baroclinic flow, coupled with the reduced influence of freshwater discharge, alters the balance of sediment fluxes implied by the condition of morphodynamic equilibrium (Eq. 6). Sediment flux in the upstream direction increases by 2.5 (due to baroclinic circulation), while sediment flux downstream decreases by 5/7 (freshwater discharge). Moreover, for greater depths, sediment is distributed lower in the water column (sediment Peclet number, $P e_{v}$, is increased), resulting in more upstream transport. Together, these factors move the turbidity maximum upstream by $\sim 10 \mathrm{~km}$ as depth is changed from 5 to $7 \mathrm{~m}$. Because the width of the model decays exponentially upstream ( $e$-folding scale of $20 \times 10^{3} \mathrm{~m}$ ), sediment is distributed over a smaller volume of water for $H=7 \mathrm{~m}$. As the ETZ moves upstream, its longitudinal spread is increasingly halted by the upstream boundary. Finally, the spread of SSC around the maximum is reduced as $H$ increases (see Talke et al. 2008). Combined, these effects amplify the magnitude of SSC by an order of magnitude and cause longitudinal gradients in SSC that produce turbidity currents.

The greatly amplified SSCs for a depth of $H=7 \mathrm{~m}$ implies an order of magnitude greater concentration of organic matter. This organic material is primarily responsible for the greatly decreased DO concentrations compared to $H=5 \mathrm{~m}$. Particularly near the bed, deeper water also reduces the affect of aeration and leads to greater DO depletion due to an increase in the ratios $\frac{p k_{r} c_{x d} H}{k_{L}}$ and $\frac{H k_{L}}{K_{v}}$ (see Eq. 19, Supplement S.3).

For the model estuary, the minimum in oxygen concentration closely follows the position of the maximum SSC and is 0.4 and $1.5 \mathrm{~km}$ upstream for $H=5 \mathrm{~m}$ and $H=7 \mathrm{~m}$, respectively. Moreover, the modeled spread of the low DO area $\left(<5 \mathrm{mg}^{-1}\right)$ coincides with the spread of the turbid zone. Hence, for these parameter values, the distribution of sediment is the dominant predictor of DO and longitudinal advection and diffusion of oxygen are lower-order effects.

Variation in freshwater discharge (seasonally) and mixing (e.g., due to spring-neap tidal cycle) are ubiquitous features of an estuary. Figure 10 presents the modeled effect of increasing freshwater discharge (Figs. 10a, c, e) or decreasing eddy viscosity and eddy diffusivity (Figs. 10b, 
Fig. 10 Variation in modeled circulation (top panels), SSC (middle panels), and oxygen concentrations (bottom panels) for a discharge of $160 \mathrm{~m}^{3} \mathrm{~s}^{-1}$ (a, c, e) and an eddy viscosity and eddy diffusivity of $0.0005 \mathrm{~m}^{2} \mathrm{~s}^{-1}$ $(\mathbf{b}, \mathbf{d}, \mathbf{f})$. All other parameters are set to the standard values in Table 2
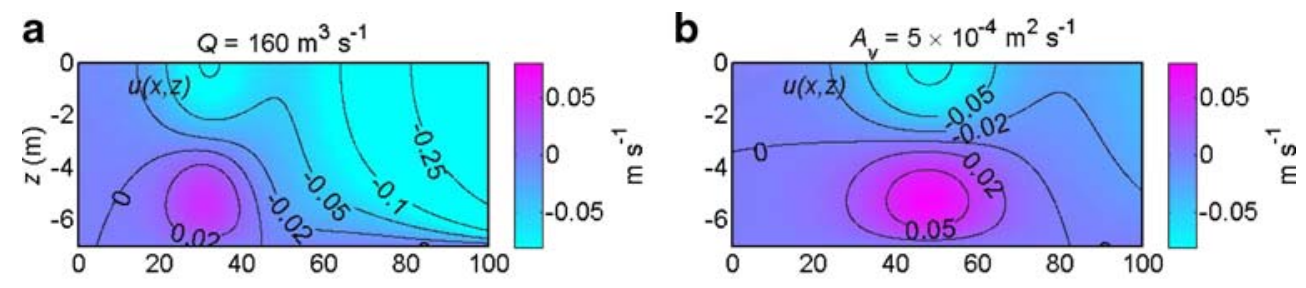

C

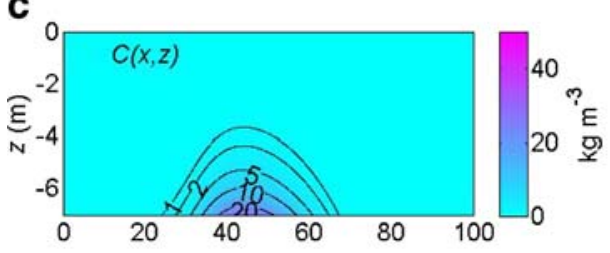

e

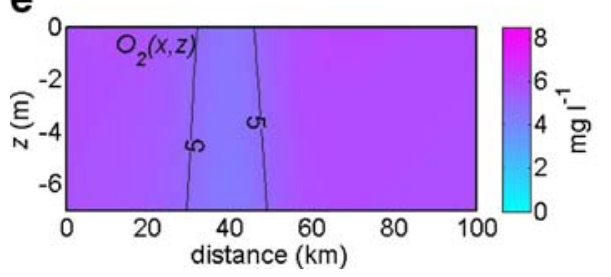

d

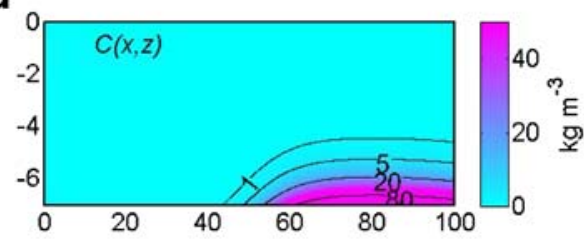

f

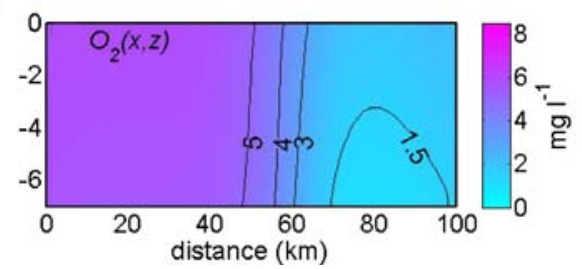

d, f) from standard conditions (Fig. 9b, d, f). Increased freshwater discharge directly increases the downstream flow, particularly near the tidal weir where the width $b$ is small. In addition, the salinity field moves and its gradient becomes steeper, leading to a greater baroclinic circulation cell that is shifted downstream by $\sim 17 \mathrm{~km}$ (Table 1; Supplement S.2). These circulation changes move the ETZ downstream, decrease the longitudinal spread of
SSC, and decrease the magnitude of SSC (due to larger width $b$ ). Increased DO concentrations result in a smaller DO sag (in the longitudinal direction) that is shifted downstream with the ETZ.

Reducing eddy viscosity $\left(A_{v}\right)$ increases baroclinic circulation (see Eq. 5), while decreasing eddy diffusivity $\left(K_{v}=\right.$ $A_{v}$ ) causes sediment to accumulate closer to the bed (Fig. 10). Together, the resulting increase in near-bed
Fig. 11 Sensitivity in the modeled longitudinal profile of bottom $(z=-H)$ DO concentration to prescribed variations in sediment oxygen demand $S_{b}(\mathbf{a})$, suspended sediment oxygen demand $k_{r}(\mathbf{b})$, aeration $k_{L}(\mathbf{c})$, and temperature $T(\mathbf{d})$. The SSC profile for each case found used the standard parameters in Table 2. The solution using the standard DO parameters in Table 1 is given by the solid magenta (dark shaded) profile in $\mathbf{a}, \mathbf{b}$, and $\mathbf{c}$
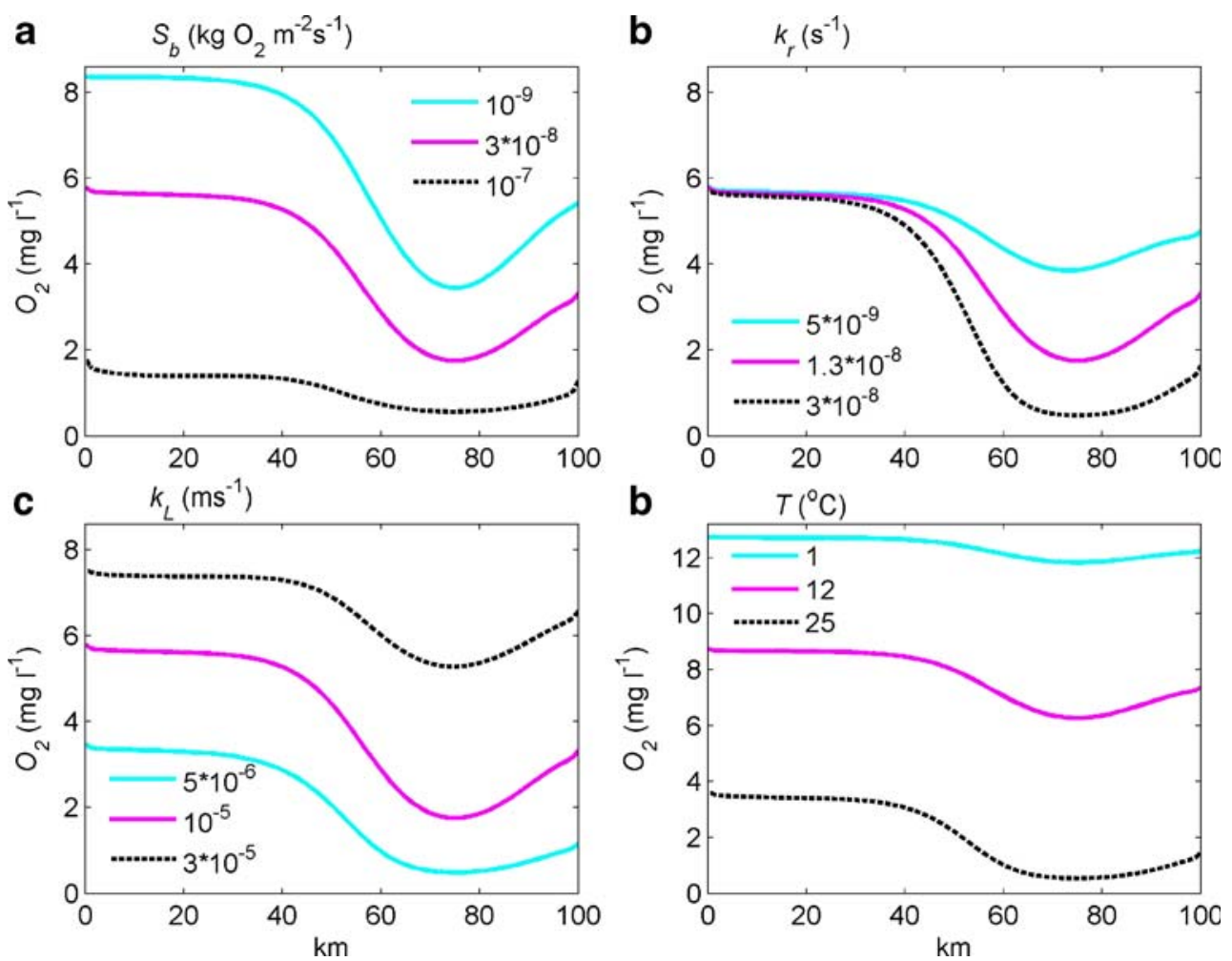
sediment flux (term $u C$ in Eq. 6) moves suspended sediment closer to the boundary, where smaller width and reduced longitudinal spread (due to the upstream boundary) amplify SSCs. These patterns result in greater DO depletion and an upstream movement in the DO minimum. As with the other results (see also supplement S.3), the longitudinal variation in DO is set primarily by the longitudinal variation in SSC; without SSC variation, DO in Eq. 13 is primarily set by a vertical (1D) balance.

A final sensitivity study (Fig. 11) shows changes to the longitudinal distribution of bottom DO $(z=-H)$ as parameters associated only with the oxygen model (i.e., $S_{b}, k_{L}, k_{r}$, and $T$ ) are varied. In each case, the tidally averaged circulation and equilibrium distribution of SSC resulting from Table 3 default conditions and displayed in Fig. 9b, d, respectively, are used. For $S_{b}, k_{L}$, and $T$, the range of values in Fig. 11 reflects the reported range of each parameter (see "Oxygen Consumption by Suspended Sediment Oxygen Demand"). For the refractory decay coefficient of organic material, $k_{r}$, we test the response of a factor of $\sim 2.5$ change in either direction.

Increasing bed demand $S_{b}$ (Fig. 11a), organic material decay coefficient $k_{r}$ (Fig. 11b), and temperature $T$ (Fig. 11d) results in increased oxygen depletion throughout the model estuary, while increasing aeration $k_{L}$ (Fig. 11c) produces more oxygenated conditions (note that increasing $T$ raises $S_{b}$ and $k_{r}$ simultaneously). The position of the DO minimum changes by several kilometers between different cases, indicating the nonnegligible-but second orderaffect of advection and horizontal diffusion. An approximately linear response to changing conditions is observed for aeration above 2 to $3 \mathrm{mg}^{-1}$, as suggested by the simplified analytical expression (Eqs. 18 and 19): tripling the standard aeration coefficient results in a threefold increase in minimum DO. Decreasing bed demand $S_{b}$ to $10^{-9} \mathrm{~kg} \mathrm{O}_{2} \mathrm{~m}^{-2} \mathrm{~s}^{-1}$ approximately doubles the minimum DO concentration (Fig 11a). The less than proportional response occurs because organic material in the water column (given by $k_{r}$ ) continues to deplete oxygen. A similar behavior is observed for decreasing $k_{r}$ (Fig. 11b).

However, the longitudinal extent of stressed $\left(<5 \mathrm{mg} \mathrm{l}^{-1}\right)$ and hypoxic DO conditions responds nonlinearly to changes in the parameters. For example, halving the aeration coefficient from the standard condition produces hypoxic conditions over $\sim 25 \mathrm{~km}$, while tripling aeration removes the stressed area completely (Fig. 11c). Increasing temperature decreases the saturation DO concentration and magnifies both $S_{b}$ and $k_{r}$; hence, a doubling of temperature from $12^{\circ} \mathrm{C}$ to $25^{\circ} \mathrm{C}$ shifts the system from well oxygenated to hypoxic. The modeled range of $T$ mirrors seasonal changes observed in the river Ems (as low as $0-1{ }^{\circ} \mathrm{C}$ in winter and $20-25^{\circ} \mathrm{C}$ in summer) and helps explain why hypoxia occurs primarily in the summer months.

\section{Discussion}

The model we present differs from other models of oxygen depletion in that we consider the depletion of oxygen from a spatially variable SSC. Other models, for example Lin et al. (2006), investigate how gravitational circulation and river discharge affect estuarine residence time and stratification and therefore the vertical profile of oxygen. In these environments, the mechanism of oxygen depletion is the decay of algae (and is thus eutrophication-driven) and a constant sediment oxygen demand. Hence, the interaction of nutrients and algae and their residence time controls oxygen depletion.

In highly turbid estuaries, such as the Ems, enormous amounts of SSC are trapped in the ETZ (Figs. 2, 3, 4, and 5). In this situation, a dominant control on the depletion of oxygen becomes the magnitude and distribution of organic matter that is attached to SSCs. This oxygen demand from organic material is neither confined to the bed (as a boundary condition) nor spatially constant over the estuary. A minimum of DO occurs near the turbidity maximum, which is formed when the vertically integrated fluxes of sediment from gravitational circulation and freshwater discharge balance each other. The convergence of these sediment fluxes is balanced by counter-gradient fluxes caused by turbidity currents and longitudinal dispersion (i. e., fluxes proportional to $\mathrm{d} c_{b} / \mathrm{d} x$; see Eqs. 5 and 6). Changes to the physical parameters that control these fluxes (e.g., salinity field, freshwater discharge, sediment supply, depth, mixing, etc.) produce a new distribution of SSC and a different spatial variation in oxygen demand and DO. Hence, the factors which alter SSC distribution drive changes to DO rather than the input of nutrients or the residence time of water.

Qualitatively, the model results explain the plummet in DO concentrations since deepening the Ems estuary from 5 to $7 \mathrm{~m}$ between 1985 and 1994. The $H^{3}$ dependence of gravitational circulation produces an inherently nonlinear response in SSC transport, which is amplified further by the depth dependence of the area-averaged freshwater discharge and the vertical distribution of SSC. Together, these physical processes cause an order of magnitude increase in SSC and produce a large zone of depleted DO for an increase from 5 to $7 \mathrm{~m}$ (Fig. 9). Additional factors driving DO downwards include the likely decrease in eddy diffusivity and eddy viscosity that occurs due to sediment-induced stratification (e.g., Munk and Anderson 1948). Other variations in mixing - such as the springneap cycle-likely drive changes to the ETZ and low DO zone.

Seasonal variation in estuarine DO is driven both by hydrology and water temperature. Depleted DO concentrations occur during the summer months because of low 
freshwater discharge (which moves the turbidity maximum upstream and amplifies SSC) and elevated temperature (which lowers DO saturation and increases decay rates of suspended organic matter and SOD). By contrast, greater discharge - which occurs during storm events in the winter - decreases SSC and organic matter concentrations by moving the ETZ downstream (van Beusekom and de Jonge 1998; Fig. 10). These conditions combine together with lower temperatures to produce an oxygenated water column in winter.

In ecological terms, the impact of a hypoxic zone is measured by the area of a water body that dips below a biologically critical threshold such as 5 or $2 \mathrm{mg}^{-1}$. Since the modeled oxygen depletion depends on SSC distribution, this equivalently reduces to the length scale for which SSC is above a certain threshold. The idealized model suggests that the length scale depends upon the total amount of sediment available for resuspension, the position of the turbidity maximum, and the relative spread of SSC from the maximum (see also Supplement S.3). Changes to organic decay rates, reaeration, and temperature also affect the size of a depleted oxygen zone and combine together with the SSC distribution to make the system sensitive to relatively small changes in its parameters.

The idealized model we present for the depletion of oxygen makes simplifying assumptions about both physical and biological processes in order to understand, at a process level, the important factors that affect DO depletion from suspended organic matter. The tidally averaged model of circulation and SSC distribution neglect tidally varying processes (e.g., settling lag, periodic salinity stratification, etc.) that influence circulation and the fluxes of sediment in an estuary. Our assumption of constant eddy diffusivity possibly overestimates vertical mixing of DO, particularly in the fluid mud layer, though field results suggest that topbottom variation is small and generally less than $2 \mathrm{mg} \mathrm{l}^{-1}$. Depth and bathymetry effects are likely important, particularly in the less uniform outer estuary. In the oxygen mass balance, we make the further simplifying assumption that model parameters such as the aeration coefficient, the organic matter decay coefficient, and the sediment oxygen demand are constant. In a real estuary, input of organic matter from the rivers and ocean likely cause variation in the decay coefficient, as do phytoplankton detritus, zooplankton detritus, remains of vascular plants, peat, and other sources of carbon. Measurements in the Ems show that organic material is $\sim 10 \%$ of the SSC for most of the turbid zone, except near the weir where organic material is $\sim 20 \%$ of SSC and has a larger rate of decay (A. Scholl, personal communication). Greater concentrations of less refractory material near the weir may explain the divergence between modeled and measured results near the weir (compare Figs. 2 and 9).
The model assumes that concentrations of algae and other input material are small compared to the mass of organic material trapped at the turbidity maximum and contribute negligibly to oxygen demand. Given the light limitation in highly turbid waters, phytoplankton production is significant only when SSC is low and is thus away from our zone of interest (e.g., the outer estuary). Similarly, aeration caused by primary production is neglected since the available algae contribute primarily to respiration. For simplicity, the effect of the reduction and oxidation of chemical compounds (e.g., Fe, Mn, and nutrient compounds) and neutrally buoyant colloidal matter on oxygen depletion are also not considered. A complete model of oxygen depletion must include these additional terms and vary them in time and space; however, we explicitly restrict the parameter complexity in order to gain insight into the fundamental effect of sediment dynamics on DO. The overall good qualitative agreement between measurements and the model validates this approach.

\section{Conclusions}

Measurements in the Ems estuary show that near-bed SSCs exceeding $50 \mathrm{~kg} \mathrm{~m}^{-3}$ coincide with stressed $\left(<5 \mathrm{mg} \mathrm{l}^{-1}\right)$ and hypoxic $\left(<2 \mathrm{mg} \mathrm{l}^{-1}\right)$ DO concentrations. To a first order approximation, the oxygen depletion is proportional to $\mathrm{SSC}$, with the depletion rate decreasing as temperature falls or as anoxic conditions are approached. The zone of depleted oxygen occurs in the estuarine turbidity zone (salinity range of $0.5-2 \mathrm{psu}$ ), which moves as freshwater discharge changes. Over the past two decades, the duration of stressed conditions during summer has increased from 10 to 20 days to more than 100 days, likely from increased SSCs.

The physical and biological processes that contribute to oxygen depletion in turbid estuaries are investigated with an idealized model that simplifies estuarine geometry and bathymetry and uses tidally averaged governing equations to investigate first-order effects. The depletion rate of DO is assumed to be proportional to SSC, and model calibration to the data shows that the decay rate is extremely refractory. Aeration at the surface provides a source of oxygen, while a prescribed oxygen demand at the bed depletes oxygen. Within the model domain, DO is found by numerically solving an advection-diffusion equation with a sink term, with analytical solutions used for velocity and SSC inputs. At the upstream and downstream model boundaries, DO is approximated by using a $1 \mathrm{D}$ vertical water column model which assumes that horizontal flux terms are negligible.

The modeled depletion of oxygen in the water column is primarily a balance between aeration and the oxygen demand from both the bed (SOD) and suspended sediment. 
Horizontal advection and diffusion are second-order effects that modify, but do not control, the distribution of DO. Above 2 to $3 \mathrm{mg} \mathrm{l}^{-1}$, the oxygen depletion near the surface increases approximately linearly with increases in the depth-averaged SSC, depth, organic material decay coefficient, and SOD. Near-bed DO concentrations are less than at the surface and are further reduced by increasing depth or reducing mixing, which hinders the transmission of surface aeration.

Over the estuary, increases in near-bed upstreamdirected currents move the ETZ upstream and amplify SSC and oxygen demand, primarily because suspended sediment is distributed over a smaller volume of water. Hence, the nonlinear dependency of baroclinic circulation on $H^{3}$, coupled with the $H^{1}$ dependence of currents from freshwater discharge, results in a nonlinear DO response as depth is changed. Variations in the longitudinal spread of SSC around the maximum, which are set by hydrodynamic parameters, also affect oxygen demand. Increasing the relative amount of SSC near the bed (by increasing $P e_{v}=w_{s} H / K_{v}$ ) both amplifies the effect of near-bed upstream currents and alters the distribution of SSC. Therefore, the coupled effect of mixing $\left(A_{v}\right.$ and $\left.K_{v}\right)$ on both circulation and vertical SSC distribution produces a nonlinear DO response. Hence, for a turbid estuary, a dominant control on oxygen depletion is the SSC dynamics, rather than the residence time of water or nutrient inputs.

Both model results and field measurements show a strong seasonal variation in DO concentrations that are caused both by temperature-induced variation in the decay rates of organic material (i.e., changing $k_{r}$ and $S_{b}$ ) and oxygen saturation and by variation in the hydrologic cycle which typically produces low discharge-and high organic material concentrations - during the summer months. This seasonal cycle has been altered by deepening the river Ems from 5 to $7 \mathrm{~m}$, which has moved the ETZ upstream and amplified SSC. Thus, anthropogenically driven changes to the sediment dynamics explain the reduction in average summertime DO by as much as 2 to $3 \mathrm{mg}^{-1}$ over the past several decades and the much greater occurrence of hypoxic events.

Acknowledgments Many thanks to Verena Brauer, Robbert Schippers, Karin Huijts, Marcel van Maarseveen, and Frans Buschman for logistical support during experiments. Thanks also to Martin Krebs and Helge Juergens from WSA Emden, Rewert Wurpts, Uwe Boekhoff, and Baerbel Amman from Niedersachsen Ports (NP), Andreas Engels from NLWKN, and Christine Habermann from the Bundesanstalt fuer Gewaesserkunde (BfG). Andreas Scholl of BfG is especially thanked for his extensive personal communication. The crews of the Delphin (NP) and the WSA Friesland are also thanked. This work was funded by LOICZ project 014.27.013 (Land Ocean Interaction in the Coastal Zone), and administered by NWO-ALW, the Netherlands Organization for Scientific Research.

\section{Appendix}

The functions $k_{1}$ and $k_{2}$ produce the vertical structure of currents driven by salinity gradients and turbidity gradients, respectively (Eq.5), and depend on the vertical coordinate and the sediment Peclet number $P e_{v}=w_{s} H / K_{v}$.

$k_{1}(\zeta)=\left(1-9 \zeta^{2}-8 \zeta^{3}\right)$

$k_{2}\left(\zeta, P e_{v}\right)=12 G_{1} P e_{v}^{-4} \exp \left(-P e_{v}(1+\zeta)\right)$,

where $G_{1}$ is defined as

$$
\begin{aligned}
G_{1}= & 4 P e_{v}+6\left(-1+\frac{1}{3} P e_{v}+\zeta^{2}-P e_{v} \zeta^{2}\right) \exp \left(P e_{v}(1+\zeta)\right) \\
& +(1+\zeta) \exp \left(P e_{v} \zeta\right)\left\{6-6 \zeta+(1+3 \zeta) P e_{v}^{2}\right\}
\end{aligned}
$$

The expressions $T_{s}, T_{t}, T_{Q}$, and $T_{K}$ in Eqs. 13, 14, and 15 are defined as follows:

$$
\begin{aligned}
& T_{S}=\int_{-1}^{0} k_{1}(\zeta) \exp \left(-P e_{v}(\zeta+1)\right) \mathrm{d} \zeta \\
& T_{T}=\int_{-1}^{0}\left(1-\zeta^{2}\right) \exp \left(-P e_{v}(\zeta+1)\right) \mathrm{d} \zeta \\
& T_{Q}=\int_{-1}^{0} k_{2}\left(\zeta, P e_{v}\right) \exp \left(-P e_{v}(\zeta+1)\right) \mathrm{d} \zeta \\
& T_{K_{h}}=\int_{-1}^{0} \exp \left(-(\zeta+1) P e_{v}\right) \mathrm{d} \zeta .
\end{aligned}
$$

By solving, these expressions reduce to functions of the sediment Peclet number $P e_{v}$ :

$$
T_{S}=\frac{1}{P e_{v}^{4}}\left\{\left(-48+P e_{v}^{3}-18 P e_{v}\right) \exp \left(-P e_{v}\right)+48-30 P e_{v}+6 P e_{v}^{2}\right\},
$$

$T_{T}=144 G_{2} P e_{v}^{-7} \exp \left(-2 P e_{v}\right)$

$$
\begin{gathered}
G_{2}=-1+\frac{1}{12} P e_{v}^{4}+P e_{v}^{2}+\frac{1}{2} P e_{v}^{3}+\left(-2 P e_{v}-P e_{v}^{2}+\frac{1}{3} P e_{v}^{3}+2\right) \\
\exp \left(P e_{v}\right)+\left(-1-P e_{v}^{2}+\frac{1}{6} P e_{v}^{3}+2 P e_{v}\right) \exp \left(2 P e_{v}\right),
\end{gathered}
$$

$T_{Q}=\frac{-2}{P e_{v}^{3}}\left\{1-P e_{v}+\left(-1+\frac{1}{2} P e_{v}^{2}\right) \exp \left(-P e_{v}\right)\right\}$

$T_{K_{h}}=\frac{1-\exp \left(-P e_{v}\right)}{P e_{v}}$ 


\section{References}

APHA. 1992. Standard methods for the examination of water and wastewater, 18th ed. Washington, DC: American Public Health Association, American Waterworks Association, Water Environment Federation.

Baretta, J.W. and P. Ruardij (eds). 1988. Tidal flat estuaries: Simulation and analysis of the Ems estuary. Ecological studies, vol. 71, 353. Heidelberg: Springer.

Benoit, P., Y. Gratton, and A. Mucci. 2006. Modeling of dissolved oxygen levels in the bottom waters of the Lower St. Lawrence estuary: Coupling of benthic and pelagic processes. Marine Chemistry 102: 13-32. doi:10.1016/j.marchem. 2005.09.015.

Borsuk, M.E., C.A. Stow, R.A. Luettich Jr., H.W. Paerl, and J.L. Pinckney. 2001. Modelling oxygen dynamics in an intermittently stratified estuary: Estimation of process rates using field data. Estuarine, Coastal and Shelf Science 52: 33-49.

Chapra, S.C. 1997. Surface water-quality modeling. New York: McGraw-Hill.

Colijn, F. 1982. Light absorption in the waters of the Ems-Dollard estuary and its consequences for the growth of phytoplankton and microphytobenthos. Netherlands Journal of Sea Research 15: 196-216.

Cox, B.A. 2003. A review of dissolved oxygen modeling techniques for lowland rivers. The Science of the Total Environment 314316: 303-334. doi:10.1016/S0048-9697(03)00062-7.

Dai, M., X. Guo, W. Zhai, L. Yuan, B. Wang, L. Wang, P. Cai, T. Tang, and W.J. Cai. 2006. Oxygen depletion in the upper reach of the Pearl River estuary during a winter drought. Marine Chemistry 102: 159-169. doi:10.1016/j.marchem.2005.09.020.

de Jonge, V.N. 2000. Importance of temporal and spatial scales in applying biological and physical process knowledge in coastal management, an example for the Ems estuary. Continental Shelf Research 20: 1655-1686.

de Jonge, V.N. and L.A. Villerius. 1989. Possible role of carbonate dissolution in estuarine phosphate dynamics. Limnology and Oceanography 34: 332-340.

Diaz, R.J. and R. Rosenberg. 1995. Marine benthic hypoxia: A review of its ecological effects and the behavioral responses of benthic macrofauna. Oceanography and marine and biology: An annual review 33: 245-303.

Engle, V.D., J.K. Summers, and J.M. Macauley. 1999. Dissolved oxygen conditions in northern Gulf of Mexico estuaries. Environmental Monitoring and Assessment 57: 1-20.

Essink, K. 2003. Response of an estuarine ecosystem to reduced organic waste discharge. Aquatic Ecology 37(1): 65-76.

Fang, T.H. and C.L. Lin. 2002. Dissolved and particulate trace metals and their partitioning in a hypoxic estuary: The Tanshui Estuary in northern Taiwan. Estuaries 25: 598-607.

Friedrichs, C.T., B.D. Armbrust, and H.E. de Swart. 1998. Hydrodynamics and equilibrium sediment dynamics of shallow, funnelshaped tidal estuaries. In Physics of estuaries and coastal seas, ed. J. Dronkers and M.B.A.M. Scheffers, 315-327. Rotterdam: Balkema.

Garban, B., D. Olivon, M. Poulin, V. Gaultier, and A. Chesterikoff. 1995. Exchanges at the sediment-water interface in the river Seine, downstream from Paris. Water Research 29: 473-481.

Garnier, J., P. Servais, G. Billen, M. Akopian, and N. Brion. 2001. Lower Seine River and estuary (France) carbon and oxygen budgets during low flow. Estuaries 24: 964-976.

Hagy, J.D. and M.C. Murrell. 2007. Susceptibility of a northern Gulf of Mexico estuary to hypoxia: An analysis using box models. Estuarine, Coastal and Shelf Science 74: 239-253. doi:10.1016/j. ecss.2007.04.013.
Hagy III, J.D., W.R. Boyton, C.W. Keefe, and K.V. Wood. 2004. Hypoxia in Chesapeake Bay, 1950-2001: Long-term change in relation to nutrient loading and river flow. Estuaries 27: 634-658.

Hansen, D.V. and M. Rattray Jr. 1965. Gravitational circulation in straits and estuaries. Journal of Marine Research 23: 104-122.

Helder, W. and P. Ruardij. 1982. A one-dimensional mixing and flushing model of the Ems-Dollart estuary: calculation of time scales at different river discharges. Netherlands Journal of Sea Research 15: 293-312.

Jensen, J., C. H. Mudersbach, and C. Blasi. 2003. Hydrological changes in tidal estuaries due to natural and anthropogenic effects. In Proceedings of the 6th International MEDCOAST 2003 Conference, Ravenna, Italy.

Kineke, G.C. and R.W. Sternberg. 1992. Measurements of highconcentration suspended sediments using the optical backscatter sensor. Marine Geology 108: 253-258.

Krebs, M., and H. Weilbeer, 2008. Ems Dollart estuary. Die Küste 74.

Lin, J., L. Xie, L.J. Pietrafesa, J. Shen, M.A. Mallin, and M.J. Durako. 2006. Dissolved oxygen stratification in two micro-tidal partially-mixed estuaries. Estuarine, Coastal and Shelf Science 70: 423-437. doi:10.1016/j.ecss.2006.06.032.

Lung, W.S. and A.J. Nice. 2007. Eutrophication model for the Patuxent estuary: Advances in predictive capabilities. Journal of Environmental Engineering 133: 917-930. doi:10.1061/ (ASCE)0733-9372(2007)133:9(917).

May, C.L., J. Koseff, L.V. Lucas, J.E. Cloern, and D.H. Schoellhamer. 2003. Effects of spatial and temporal variability of turbidity on phytoplankton blooms. Marine Ecology Progress Series 254: $111-128$

Monismith, S.G., W. Kimmerer, J.R. Burau, and M.T. Stacey. 2002. Structure and flow-induced variability of the subtidal salinity field in Northern San Francisco Bay. Journal of Physical Oceanography 32: 3003-3019.

Munk, W.H. and E.R. Anderson. 1948. Notes on a theory of the thermocline. Journal of Marine Research 7: 276-295.

Ni, J., L. Sun, and W. Sun. 2007. Modification of chemical oxygen demand monitoring in the Yellow River, China, with a high content of sediments. Water Environment Research 79: 23362342. doi:10.2175/106143007X183790.

Nestlerode, J.A. and R.J. Diaz. 1998. Effects of periodic environmental hypoxia on predation of a tethered polychaete, Glycera americana: implications for trophic dynamics. Marine Ecology Progress Series 172: 185-195.

Odd, N.V.M. 1988. Mathematical modeling of mud transport in estuaries. In Physical processes in estuaries, ed. J. Dronkers and W. van Leussen, 503-531. Berlin: Springer.

Officer, C.B. 1976. Physical oceanography of estuaries (and associated coastal waters), 125-129. Wiley: New York.

Talke, S.A., H.E. de Swart, and H.M. Schuttelaars. 2008. An analytical model for the equilibrium distribution of sediment in an estuary. In River, coastal and estuarine morphodynamics, ed. C.M. Dohmen-Janssen and S.J.M.H. Hulscher, 403-412. London: Taylor \& Francis.

Talke, S.A., H.E. de Swart, and H.M. Schuttelaars. 2009. Feedback between residual circulations and sediment distribution in highly turbid estuaries: an analytical model. Continental Shelf Research 29: 119-135. doi:10.1016/j.csr.2007.09.002.

Thouvenin, B., P. Le Hir, and L.A. Romana. 1994. Dissolved oxygen model in the Loire Estuary. In Changes in fluxes in estuaries, implications from science to management, ed. K.R. Dyer and R.J. Orth, 169-178. Fredensborg: Olsen and Olsen.

Uncles, R.J., I. Joint, and J.A. Stephens. 1998. Transport and retention of suspended particulate matter and bacteria in the Humber-Ouse Estuary, United Kingdom, and their relationship to hypoxia and anoxia. Estuaries 21: 597-612. 
van Beusekom, J.E.E. and V.N. de Jonge. 1998. Retention of phosphorus and nitrogen in the Ems estuary. Estuaries 21: 527-539.

van Es, F.B., M.A. van Arkel, L.A. Bouwman, and H.G.J. Schröder. 1980. Influence of organic pollution on bacterial macrobenthic and meiobenthic populations in intertidal flats of the Dollard. Netherlands Journal of Sea Research 14: 288-304.

Warner, J.C., W.R. Geyer, and J.A. Lerczak. 2005. Numerical modeling of an estuary: A comprehensive skill assessment.
Journal of Geophysical Research 110: CO50001. doi:10.1029/ 2004JC002691.

Wei, H., Y. He, Q. Li, Z. Liu, and H. Wang. 2007. Summer hypoxia adjacent to the Changjiang Estuary. Journal of Marine Systems 67: 292-303. doi:10.1016/j.jmarsys.2006.04.014.

Wurpts, R. and P. Torn. 2005. 15 years experience with fluid mud: definition of the nautical bottom with rheological parameters. Terra et Aqua 99: 22-32. 